\title{
RESEARCH
}

Open Access

\section{Predicting the effectiveness of protected areas of Natura 2000 under climate change}

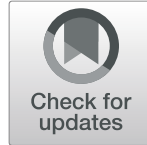

Mst. Umme Salma Nila', Carl Beierkuhnlein ${ }^{1,2}$, Anja Jaeschke², Samuel Hoffmann² and Md Lokman Hossain ${ }^{1,34^{*}}$ (D)

\begin{abstract}
Background: Protected areas (PAs) are aimed to hold the environmental conditions that facilitate species and ecosystems to persist. PAs can become climatically unsuitable and unable to sustain their current number of species under climate change. The Natura 2000 (N2K) is the largest coordinated conservation tool assigned to maintain the long-term survival of Europe's most significant species and habitats. In attempting to understand the effectiveness of PAs in the face of climate change scenarios, we tested two hypotheses: (1) PAs in the Alpine and the Boreal biogeographical regions will experience more newly emerged climate conditions (hotter and drier) compared to the climate representation of other biogeographical regions under future climate in Europe and (2) PAs in the Mediterranean and the Continental biogeographical regions will face more consistency in climate conditions due to less area of disappearing and novel climate in future.
\end{abstract}

Methods: Current climate data (1960-1990) and projections for 2050 and 2070 of PAs of N2K were extracted from WorldClim global climate data. Principal components analysis (PCA) was performed to construct climate space for the PAs across the biogeographical regions based on 19 climatic variables assessed at 5-km resolution. ArcMap 10.1 was used to map the location of the novel and disappearing climates.

Results: PAs in the Alpine region will experience more novel climate conditions in the future compared to other biogeographical regions. The future projections showed that $17.70 \%$ of the PAs in the Alpine region will experience novel climate by 2070. Considerable climate consistency was observed in the PAs in the Continental region compared to the other biogeographical regions. Our results showed that about $176 \mathrm{~km}^{2}$ of the selected PAs in the Continental region will face new emerging climate, while about $110 \mathrm{~km}^{2}$ will disappear under RCP 8.5 scenario. The prediction also revealed that in the Mediterranean region 08 PAs will experience novel climate and $786 \mathrm{~km}^{2}$ areas in these PAs will face disappearing climate by 2070. We found that fewer areas of PAs in the Boreal regions will experience disappearing climate in both the scenarios.

Conclusions: The portion of novel climate conditions can be seen as a future opportunity to assign new reserves for the species. Our study highlights the importance of conservation planning to increase the connectivity between PAs, identifying novel conservation zones to maximize representation of habitats during the emerging climatic changes as well as designing strategies, management, and monitoring of the individual PAs.

Keywords: Biodiversity conservation, Biogeographical region, Climate change, Climate scenarios, Natura 2000, Protected areas

\footnotetext{
* Correspondence: lokmanbbd@gmail.com

${ }^{1}$ Global Change Ecology, International Elite Study Programme, University of

Bayreuth, Universitätsstraße 30, 95447 Bayreuth, Germany

${ }^{3}$ Department of Geography, Hong Kong Baptist University, 15 Baptist

University Road, Kowloon Tong, Hong Kong

Full list of author information is available at the end of the article
} 


\section{Introduction}

The conservation of biodiversity is a crucial priority because species have been declining and becoming extinct over the last decades (Willis et al. 2009). Currently, over 200,000 protected areas (PAs) encompass $14 \%$ of the world's landmass and to some extent more than $3 \%$ of the marine environment (Deguignet et al. 2014; Jenkins and Joppa 2009). These areas represent valuable habitat for rare and threatened species and provide shelter for species from a human-dominated world (Langdon and Lawler 2015). The coverage of PAs including nationally and locally designated sites on land, coastal, and marine ecosystems went up to 1.34 million $\mathrm{km}^{2}$ in European countries in 2018 and cover approximately 25\% of terrestrial land and inland waters (EEA 2019). Europe has 120,000 sites, and the number of PAs are quite larger than that of other regions in the world (EEA 2019).

The twenty-first century is projected to witness unprecedented climate changes, and average temperature rise could be as high as $6^{\circ} \mathrm{C}$ by 2100 (IPCC 2013). As few species already reacted to extreme events (Hossain and Beierkuhnlein 2018) and to temperature rise of $0.6{ }^{\circ} \mathrm{C}$, apparently more significant consequences for species and biological systems are likely to happen later on (Root et al. 2003). Expecting significant influences on the global distribution of species by recent climate warming (Parmesan and Yohe 2003; Dawson et al. 2011) makes conservation biologist more concerned about the impact on biodiversity (Brooks et al. 2006). Many physiological and ecological processes will be altered, and radical changes in species distribution might happen under future climate change scenarios (Hansen et al. 2006). One of the projected effects of global climate change is to modify the effectiveness of PAs, i.e., how well they can support species in the future. Species could adapt their niche and, therefore, remain where they are, or they could move to maintain their niche (Wiens et al. 2010). Many studies have reported the poleward shift of species distribution as a biological sign of global warming (Parmesan 2006; Root et al. 2003; Thomas and Gillngham 2015).

There is no uniform trend in changes of global hydrology in regard to the warming over the twenty-first century (EEA 2017). For example, the dissimilarity in precipitation between wet and dry regions and between wet and dry seasons will go up. By the end of the present century, the annual mean precipitation will rise in the high latitudes and mid-latitude wet regions while mid-latitude dry regions are likely to experience a decrease in precipitation under severe climate scenario (Hartmann et al. 2013). Since average global temperature rises, more intense and frequent precipitation will become profound in the wet tropical regions. In Europe, spatial and temporal variability is observed more in the changes of precipitation compared to temperature variations (Jacob et al. 2014). In Northern Europe, precipitation has increased, especially in winter while rainfall has dropped in Southern Europe, particularly in summer (Jacob et al. 2014). Average summer precipitation has dropped by approximately $20 \mathrm{~mm}$ in the southern part of Europe whereas a rise of $18 \mathrm{~mm}$ has been observed in Northern Europe (Stocker et al. 2015).

PAs cover biodiversity and ecosystems of high conservation value. Furthermore, these areas provide a variety of services (i.e., ecosystem services), both direct and indirect, to our societies and economies (Thompson and Peepre 2014). Nonetheless, the services of PAs might undermine by climate change in those regions where the rate and magnitude are high, and shifts in vegetation communities and related wildlife species are already on the move (Rowland et al. 2016). The key to creating reactions to these changing conditions is foreseeing potential effects of changing climate on the services of PAs (Rowland et al. 2016). Moves in species' distributions because of rising annual average temperature could imply that current PAs holding particular species may not keep hold of such species in the upcoming decades (Hannah et al. 2007; Hole et al. 2009). So, the decreases of particular species directly affect the maintenance of biodiversity which can lead to a decline in species and habitat diversity (Stolton et al. 2015). Consequently, habitat provision services of PAs are highly at risk (Stolton et al. 2015). So, global climate change now considers as a significant threat to future biodiversity together with the loss of habitat and fragmentation (Willis et al. 2009). New emerging climate conditions in future pose a real threat of extinction to species. It has effect on the life cycle maintenance of species by reducing species interaction (Stolton et al. 2015). For instances, farmers will have to pollinate their crops by hand if pollinating insects are declined so dramatically (Thompson and Peepre 2014). Biodiversity distribution will certainly change due to shift in species distribution (Menendez et al. 2007) causing a decrease in species richness of particular places, for instance, species move from PAs to non-PAs (Araujo et al. 2004). So, it affects the ecosystem functioning and reduces the ability of ecosystem to provide resources (Stolton et al. 2015).

The dynamic nature and diversity of species responses to climate change pose significant difficulties for developing long-term conservation approaches. One key question is whether existing PA networks will stay active in a changing climate (Johnston et al. 2013). Nevertheless, moves in species distributions because of climate change could imply that current PAs holding particular species may not keep hold of such species in the upcoming decades (Hannah et al. 2007; Hole et al. 2009). Moreover, the climate-driven natural landscape is no 
longer static or as steady as it has been in the recent past, though the borders of PAs are usually fixed (Lovejoy 2006; Zomer et al. 2015). After arising the need to shift PA ranges in the future to track the area of suitable climate, there poses a real threat of extinction to species. So, global climate change now considers as a significant threat to future biodiversity together with the loss of habitat and fragmentation (Willis et al. 2009).

The poleward shift of species due to climate warming makes the effectiveness of PA networks more addressing issue nowadays (Leach et al. 2013). Till now, evidence for climate-driven species distribution shifts is available from northern regions where temperature gradients dominate (Parmesan and Yohe 2003; Beale et al. 2013). Indeed, future climates within a random set of sites could be as appropriate for priority species as sites within the network have been suggested by recent research on one European conservation site network (Araujo et al. 2011). Nevertheless, some other networks in Europe are anticipated to a great extent to keep up their effectiveness (Leach et al. 2013).

Rising alertness about global climate change threatening biodiversity (Pereira et al. 2010; Bellard et al. 2012) has pushed several assessments on present conservation areas about their future feasibility given anticipated changes (Araujo et al. 2004; Hannah et al. 2007; Hole et al. 2009). Several strategies and measures have put forward to conserve biological diversity by the World Conference on Biological Diversity held in Rio de Janeiro in 1992, the European Natura 2000 (N2K) network, and the Environmental Conference of the Regions of Europe.

As a key conservation instrument of Europe's biodiversity, N2K network is designed to maintain the long-term survival of most valuable species and habitats (EC 2017). This largest coordinated multinational network was adopted to conserve the most seriously threatened habitats and species across Europe in 1992 (EC 2017). At present, the N2K network includes over $788,000 \mathrm{~km}^{2}$ (18\%) of Europe's terrestrial land and 3\% of inland waters (EEA 2015a) and nearly $320,000 \mathrm{~km}^{2}(6 \%)$ of the marine territory across all $28 \mathrm{EU}$ member states (Orlikowska et al. 2016). This internationally synchronized conservation network includes 27,393 sites of PAs (EEA 2017). N2K presents a safe home to Europe's most valuable and threatened species and the habitats and is based on the 1979s Birds Directive (Special Protection Areas) and the 1992s Habitats Directive (Sites of Community Importance and Special Areas of Conservation) (EEA 2017). N2K motivates people to work along with nature rather than against it by being a much appropriate approach to conservation and sustainable use of PAs (EC 2017). It comprises protected nature reserves of private ownership without excluding human activities from those areas. Ecosystem services are provided by the N2K network worth ca 200-300 billion Euro/year (Orlikowska et al. 2016). The EU member states are promised to conserve the habitats and species mentioned in the directives (Orlikowska et al. 2016). The N2K network mainly derives from the Habitats Directive. Member states select sites based on defined scientific criteria, though the selection process differs based on which nature directives (birds or habitats) justify the establishment of the site (EC 2016). The Habitats Directive promises the protection of a broad variety of rare, threatened endemic species. Moreover, around 200 rare habitat types are marked for conservation (EC 2016a).

In attempting to identify how multiple climate factors are interrelated and may change in future in the PAs, we tested the following two hypotheses:

1. PAs in the Alpine and the Boreal biogeographical regions will experience more newly emerged climate conditions (hotter and drier) compared to the climate representation of other biogeographical regions under future climate in Europe.

2. PAs in the Mediterranean and the Continental biogeographical regions will face more consistency in climate conditions due to less area of disappearing and novel climate in future.

\section{Materials and methods \\ Study area \\ Biogeographical regions}

We selected 987 PAs out of 27,393 sites (EEA 2017), and those selected PAs are located across seven biogeographical regions (i.e., Alpine, Atlantic, Boreal, Continental, Mediterranean, Macaronesia, Pannonian) in Europe. The smallest study site is at least $5 \mathrm{~km}$, and it can easily be processed with climate data of $5-\mathrm{km}$ resolution. The geographic distribution of studied PAs used in the analysis is shown in Fig. 1.

The Alpine region Some significant mountains extended over most of the countries in Europe and the Alpine biogeographical region includes five of the longest and highest ranges in Europe (Condé and Richard 2005). This biogeographical region is characterized by a relatively cold and harsh climate regardless of its topography (Rubin et al. 2005). Climate change poses a significant threat here because a little change in climatic conditions could have devastating effects on biodiversity due to the strong environmental and climatic combination in the mountains (Orlikowska et al. 2016). There is evidence that the glaciers are decreasing (Orlikowska et al. 2016), and this region may experience more drought in future (Rubin et al. 2005).

The Atlantic region The Atlantic region consists over half of Europe's long, extensive, and varied coastline 


\section{Natura 2000 Protected Areas (across Biogeographical Regions in Europe)}

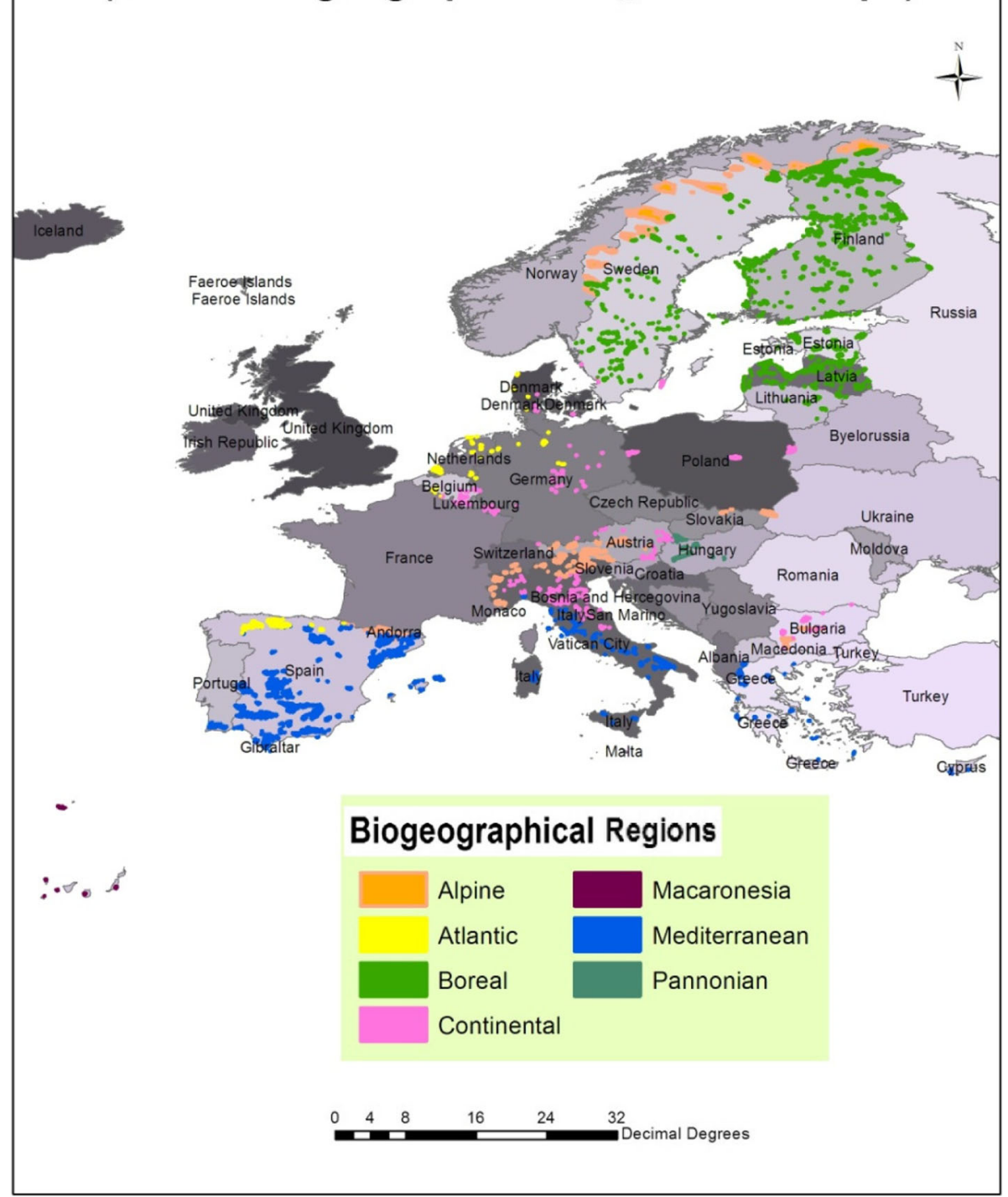

Fig. 1 Map of Europe showing the location of studied PAs belonging to the N2K network across 07 biogeographical regions

(Condé et al. 2002). Interacting with bordering the northeast Atlantic Ocean and the North Sea, the weather of this region brings warm and humid air (Sundseth 2005). This region represents a relatively small number of species despite having very favorable climate conditions with a little difference in summer and winter temperature (Sundseth 2005). High temperature, high rainfall, and a low annual variation define the of oceanic Spanish and Portuguese parts (Condé et al. 2002). This climate combination may move northwards with an increase in temperature in the region, if the rainfall remains high (Sundseth 2005).
The Boreal region In Europe, the Boreal region is the largest biogeographical region which lies less than $500 \mathrm{~m}$ above sea level (Condé et al. 2003). Also, it is Europe's forest area, dominated by conifers (Sundseth 2005a). The Boreal climate is cool-temperate, moist, and continental (Sundseth 2005a). Average annual temperature varies much over the region, for instance, monthly mean temperatures ranging from $+20^{\circ} \mathrm{C}$ in the warmest months of the warmest areas to $-15^{\circ} \mathrm{C}$ in the coldest months in the coldest areas (Sundseth 2005a). Yearly average precipitation varies from $500 \mathrm{~mm}$ to $800 \mathrm{~mm}$. No prolonged droughts are often evidenced with low evaporation (Conde et al. 2003). 
The Continental region The second largest one is the Continental biogeographical region, which is with a flat topography in the north and a hilly terrain in the south (Condé and Richard 2004). Here, the climate is consisting of warm summers and cold winters (Sundseth 2005b). The climate is defined as truly continental in the eastern parts (Sundseth 2005b). The continental weather of this region turns out to be more prominent on moving from west to east (Condé and Richard 2004).

The Macaronesian region The Macaronesian region consists of volcanic islands in the Atlantic Ocean (Sundseth 2005c). Ocean influences the regions' climate conditions (Orlikowska et al. 2016). Key features of the climate are usually dry, low seasonal temperature variation, and low amounts of precipitation (Orlikowska et al. 2016).

The Mediterranean region Hilly mountainous landscapes with inland plateaus are the physiographic characteristics of the Mediterranean region (Sundseth 2009). The unpredictable warm Mediterranean climate consists of hot summers and mild winters with diurnal temperature fluctuations (Condé et al. 2003a). The increase in temperature, longer periods of higher temperatures, and changes in precipitation are expected in the climate of this region (Orlikowska et al. 2016). Therefore, an increase in evapotranspiration due to the higher temperature could lead to an increase in the general aridity and desert conditions (Condé et al. 2003a).

The Pannonian region A large flat alluvial basin dominates the Pannonian region, and four different types of climate are profound in the region (Orlikowska et al. 2016). North-western parts are rich in precipitation whereas, a continental climate in the east characterized by lower precipitation (EEA 2009). A Mediterranean climate type presents in the south with warm summers and temperate winters while a strong influence of Atlantic-Alpine climate is noticeable in the western parts (EEA 2009).

\section{Data collection}

Current and future climate data of studied N2K PAs were extracted from WorldClim global climate data (Hijmans et al. 2005). The current climate is the average of 19601990 climates. Climate projections for 2050 (2040-60) and 2070 (2060-80) were used. Future climate for both an intermediate scenario (Representative Concentration Pathway (RCP) 4.5) and a severe scenario (RCP 8.5) were invested. Climate data resolution is $5 \mathrm{~km}$. Nineteen bioclimatic variables were used to summarize the current and future climate. These are annual mean temperature, mean diurnal range, isothermality, temperature seasonality, maximum temperature of warmest month, minimum temperature of coldest month, temperature annual range, mean temperature of wettest quarter, mean temperature of driest quarter, mean temperature of warmest quarter, mean temperature of coldest quarter, annual precipitation, precipitation of wettest month, precipitation of driest month, precipitation seasonality, precipitation of wettest quarter, precipitation of driest quarter, precipitation of warmest quarter, and precipitation of coldest quarter. Shapefiles and other attribute data of PAs and Europe were collected from European Environmental Agency (EEA 2015b). N2K viewer and the data form provide detailed information, e.g., size, location, habitat type, species, threats and pressures to PAs, and site description about every single PA. More detailed information about N2K sites was derived from the website of Protected Planet (available at: https://www.protectedplanet.net/search?q=natura+2000, Accessed on 20 June 2017).

\section{Data preparation, analysis, and mapping}

ArcMap 10.1 was used to process spatial data. Climate data for the studied PAs of different biogeographical regions were extracted from global climate data using $\mathrm{R}$ (version 3.0.0.; R Development Core Team 2013). Principal component analysis (PCA) was used to lessen the dimensionality effect of the 19 climatic variables for the current climate (McGarigal et al. 2000). Climate values for every $5-\mathrm{km}$ pixel in PAs were used as inputs to develop the PCA dimensions and factor loadings. Then future climate space was portrayed by using the same PCA model. Two axes (principal component 1 and principal component 2) were used to describe the majority of variation in the multivariate climate data to show the climate space. Each of the 5-km PAs pixels was portrayed in the two-dimensional current and future climate spaces based on two PCA axes. Since climate representation in N2K PAs likely changes in the future, the climate envelope will shift to develop new portions of the PCA space that are not present anywhere in the current climate space. To evaluate these changes, current and future climate spaces of the PAs in different biogeographical regions were compared and subsequently identified the areas of overlap and non-overlap between two spaces. The kernel density function was applied to develop a density surface of climate space based on PCA space. A polygon of current and future climate space was drawn based on the density surface. The location of the novel and disappearing climates were mapped using ArcMap 10.1.

\section{Results}

Among selected PAs across seven biogeographical regions, PAs of four regions (Alpine, Boreal, Continental, and Mediterranean) showed more significant results and, hence, explained to justify the hypothesis of this study. 


\section{Current climate space in the PAs of the Alpine biogeographical region}

In the current climate space of PAs in the Alpine biogeographical region, first three PCA axes showed the eigenvalues greater than $1(\mathrm{PC} 1=11.25, \mathrm{PC} 2=$ $4.48, \mathrm{PC} 3=1.54)$. The first and second principal component (PC) explained $60 \%$ and $23 \%$ of the variation in the current climate data, respectively. So, these two axes were used to describe multivariate climate space for the selected 125 PAs in this region.

Factor loadings of the 19 variables that entered into the analysis (Table 1) show that PC1 was positively correlated with temperature and precipitation seasonality. The temperature seasonality increased with increasing precipitation seasonality (Fig. 2). PC1 suggests that isothermality, annual precipitation, precipitation of the driest month, and precipitation of the wettest month showed negative values (Table 1). The result suggests that these four variables vary together. If one decreases, then the remaining ones tend to as well. PC2 increased with increasing annual mean temperature, mean diurnal range, max temperature of the warmest month, mean temperature of the warmest quarter, and the average temperature of the coldest quarter (Table 1).

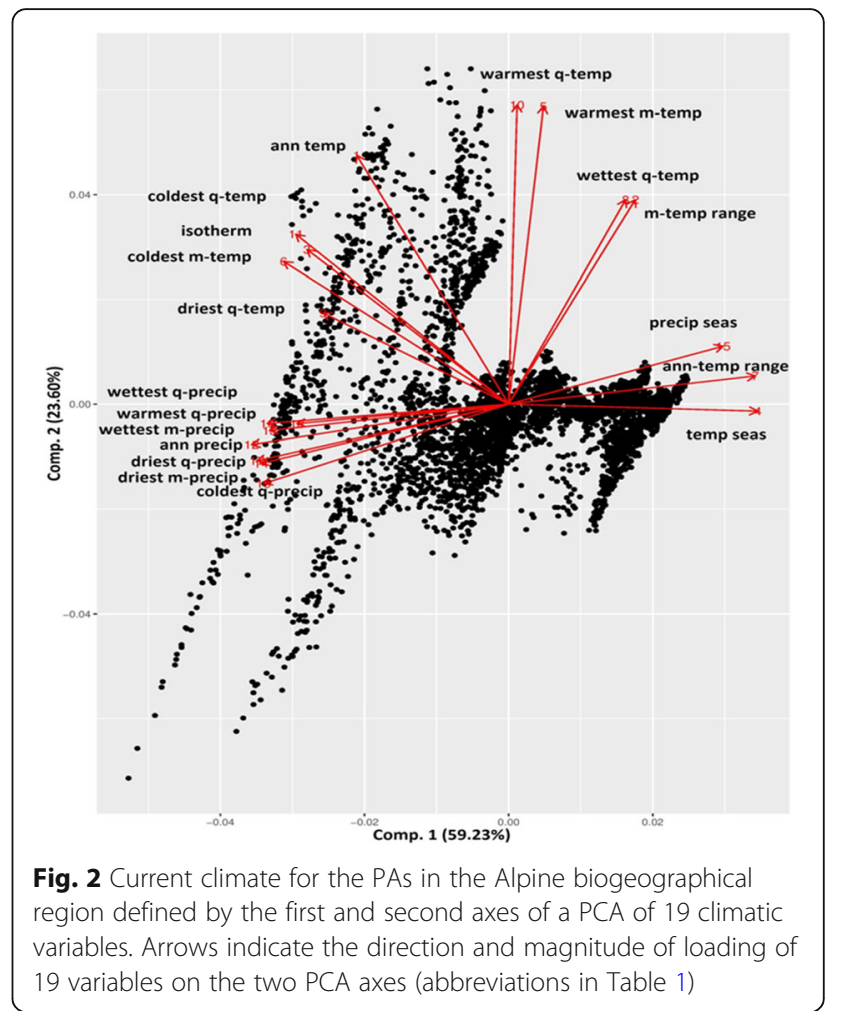

Table 1 Factor loadings of current climate (1960-1990) variables of selected 125 PAs in the Alpine biogeographical region on PCA axes 1 and 2

\begin{tabular}{|c|c|c|c|}
\hline Climate variable & Abbreviation & $\begin{array}{l}\text { Factor loadings } \\
\text { PC } 1\end{array}$ & $\begin{array}{l}\text { Factor loadings } \\
\text { PC2 }\end{array}$ \\
\hline Annual mean temperature & Ann-temp & -0.19 & 0.34 \\
\hline Mean diurnal range & M-temp range & 0.014 & 0.29 \\
\hline Isothermality & Isotherm & -0.25 & 0.20 \\
\hline Temperature seasonality & Temp seas & 0.30 & 0.019 \\
\hline Max temperature of warmest month & Warmest m-temp & -0.07 & 0.41 \\
\hline Min temperature of coldest month & Coldest m-tem & -0.27 & 0.22 \\
\hline Temperature annual range & Ann-temp rang & 0.27 & 0.09 \\
\hline Mean temperature of the wettest quarter & Wettest q-temp & 0.06 & 0.25 \\
\hline Mean temperature of the driest quarter & Driest q-temp & -0.19 & 0.21 \\
\hline Mean temperature of the warmest quarter & Warmest q-temp & -0.08 & 0.40 \\
\hline Mean temperature of the coldest quarter & Coldest q-temp & -0.26 & 0.26 \\
\hline Annual precipitation & Ann precip & -0.29 & -0.15 \\
\hline Precipitation of the wettest month & Wettest m-precip & -0.24 & -0.18 \\
\hline Precipitation of the driest month & Driest m-preci & -0.29 & -0.16 \\
\hline Precipitation seasonality & Precip seas & 0.24 & -0.01 \\
\hline Precipitation of the wettest quarter & Wettest q-precip & -0.24 & -0.17 \\
\hline Precipitation of the driest quarter & Driest q-precip & -0.30 & -0.15 \\
\hline Precipitation of the warmest quarter & Warmest q-precip & -0.18 & -0.18 \\
\hline Precipitation of the coldest quarter & Coldest q-precip & -0.28 & -0.15 \\
\hline
\end{tabular}


Future climate space in the PAs of the Alpine biogeographical region in 2050 under RCP 4.5 scenario In the future climate space of 2050 under the intermediate scenario (RCP 4.5), the first three PCs showed eigenvalues greater than $1(\mathrm{PC} 1=10.01, \mathrm{PC} 2=4.91, \mathrm{PC} 3=$ 1.9). These three PCs explained $84 \%$ of the variation in the climate data. The PC1 explained $54.18 \%$ and PC2 $25.89 \%$ of the variation in the data. The results showed that PC1 has large positive associations with seasonality and annual temperature range like the current climate space and negative associations with annual precipitation, precipitation of the driest month, precipitation of the driest quarter, and precipitation of the coldest quarter (Fig. 3; Table 2). The results showed that PC1 is positively associated with temperature and precipitation seasonality while PC2 is negatively correlated with the warmest quarter temperature variations (Table 2).

\section{Future climate space in the PAs of the Alpine} biogeographical region in 2070 under RCP 8.5 scenario In the future PCA climate space of 2070 under severe climate scenario (RCP 8.5), the first four PCs showed eigenvalues greater than $1(\mathrm{PC} 1=9.14, \mathrm{PC} 2=5.58, \mathrm{PC} 3=2.01$, PC4 $=1.26)$. The first two (PC1 and PC2) explained 77\% of the variation in the data. Temperature and precipitation seasonality will be very strongly correlated in 2070

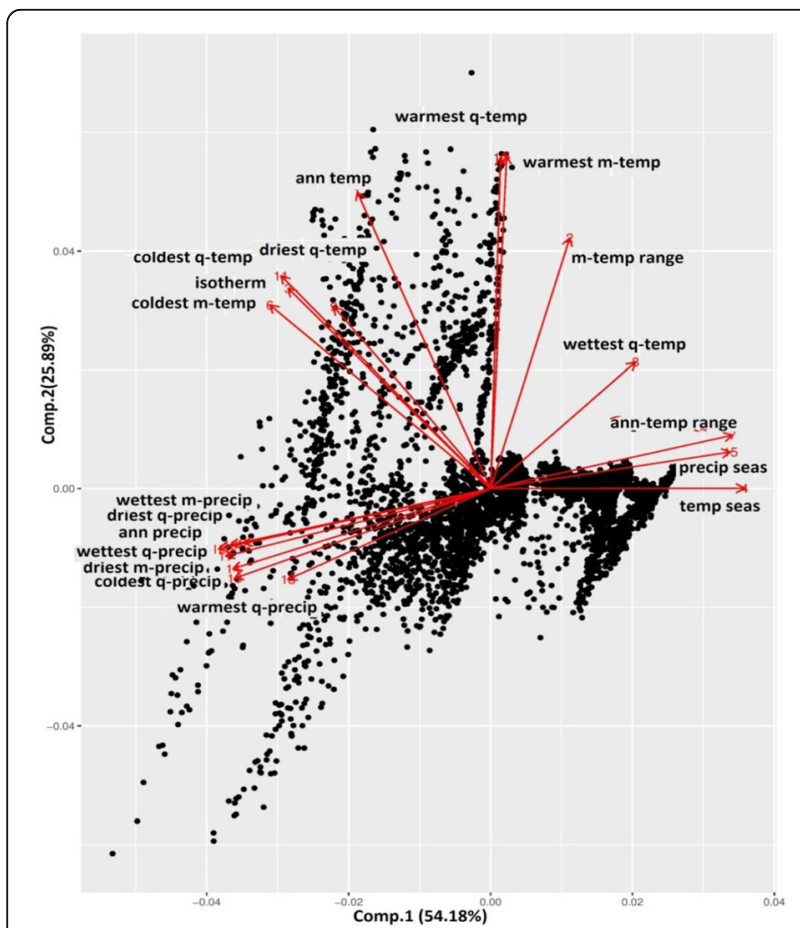

Fig. 3 Future climate 2050 (Intermediate scenarios; RCP 4.5) for PAs in the Alpine bioregion defined by the first and second axes of a PCA of 19 climatic variables. Arrows indicate the direction and magnitude of loading of 19 variables on the two PCA axes (abbreviations in Table 1) compared to the current climate (Fig. 4). Annual temperature range is strongly correlated with seasonality (Fig. 4). The results showed that temperature and precipitation seasonality is negatively correlated with annual precipitation, precipitation of the wettest month, and precipitation of the driest month. The overall climate space is strongly asymmetrical, with cooler, wetter, more seasonal temperatures and more seasonal precipitation conditions predominating (Fig. 4). The results showed that annual precipitation, precipitation of the driest quarter, and precipitation of the wettest quarter have significant positive loadings on PC1 (Table 2). PC2 suggests isothermality will increase with rising annual temperature and coldest month temperature (Table 2).

\section{Climate space shift from current to future climate (RCP 8.5) in the Alpine biogeographical region}

Figure 5 shows the novel and disappearing climates at the edges of the climate space. The results showed that 13 PAs among the 125 selected PAs in Alpine region will experience disappearing of current climate conditions, while 27 PAs will experience emerging novel climate conditions (Fig. 5) under RCP 8.5 scenarios.

\section{Current climate space in the PAs of the Boreal biogeographical region}

In the current climate space of PAs in the Boreal biogeographical region, first three PCA axes showed the eigenvalues greater than $1(\mathrm{PC} 1=9.77, \mathrm{PC} 2=6.95, \mathrm{PC} 3=$ 0.88). PC1 and PC2 explained $52 \%$ and $36 \%$ of the variation, respectively. The results revealed that annual mean temperature is negatively correlated with annual temperature range (Fig. 6). PC1 showed large positive associations with seasonality and annual temperature range like Alpine region and negative associations with annual mean temperature, mean temperature of the driest quarter, and mean precipitation of the driest quarter (Table 3). PC2 showed that annual mean temperature and the warmest quarter temperature have large negative loadings (Table 3). Mean temperature of the driest quarter and mean temperature of the coldest quarter are very strongly correlated (Fig. 6).

\section{Future climate space in the PAs of the Boreal} biogeographical region in 2070 under RCP 8.5 scenario In the future PCA climate space of 2070 under severe climate scenario, the first three PC showed eigenvalues greater than $1(\mathrm{PC} 1=10.01, \mathrm{PC} 2=5.94, \mathrm{PC} 3=1.18)$. The first two PCs explained $86 \%$ of the variation in the data. The results showed that annual mean temperature is negatively correlated with annual temperature range (Fig. 7). If the annual average temperature rises, it will decrease the difference between minimum temperatures of the coldest month and maximum temperature of the 
Table 2 Factor loadings of future climate variables (2050 and 2070) of selected 125 N2K PAs in Alpine biogeographical region on PCA axes 1 and 2

\begin{tabular}{|c|c|c|c|c|}
\hline \multirow[t]{2}{*}{ Climate variable } & \multicolumn{2}{|c|}{ Factor loadings 2050 (RCP4.5) } & \multicolumn{2}{|c|}{ Factor loadings 2070 (RCP8.5) } \\
\hline & $\overline{P C 1}$ & PC2 & $\overline{P C 1}$ & PC2 \\
\hline Ann temp & -0.14 & 0.36 & -0.19 & 0.33 \\
\hline M-temp range & -0.01 & 0.28 & -0.18 & 0.24 \\
\hline Isotherm & -0.22 & 0.25 & -0.09 & 0.34 \\
\hline Temp seas & 0.29 & -0.01 & -0.18 & -0.15 \\
\hline Warmest m-temp & -0.04 & 0.40 & -0.24 & 0.28 \\
\hline Coldest m-temp & -0.22 & 0.29 & -0.12 & 0.35 \\
\hline Ann-temp range & 0.25 & 0.08 & -0.22 & -0.05 \\
\hline Wettest q-temp & -0.12 & 0.13 & -0.11 & -0.06 \\
\hline Driest q-temp & 0.10 & 0.26 & -0.14 & 0.24 \\
\hline Warmest q-temp & -0.04 & 0.38 & -0.24 & 0.29 \\
\hline Coldest q-temp & -0.21 & 0.31 & -0.14 & 0.36 \\
\hline Ann precip & -0.33 & -0.13 & 0.31 & 0.21 \\
\hline Wettest m-precip & -0.27 & -0.15 & 0.29 & 0.17 \\
\hline Driest m-precip & -0.31 & -0.15 & 0.31 & 0.14 \\
\hline Precip seas & 0.28 & -0.03 & -0.21 & -0.17 \\
\hline Wettest q-precip & -0.28 & -0.16 & 0.31 & 0.16 \\
\hline Driest q-precip & -0.33 & -0.11 & 0.31 & 0.18 \\
\hline Warmest q-precip & -0.18 & -0.20 & 0.29 & -0.01 \\
\hline Coldest q-precip & -0.30 & -0.12 & 0.25 & 0.21 \\
\hline
\end{tabular}
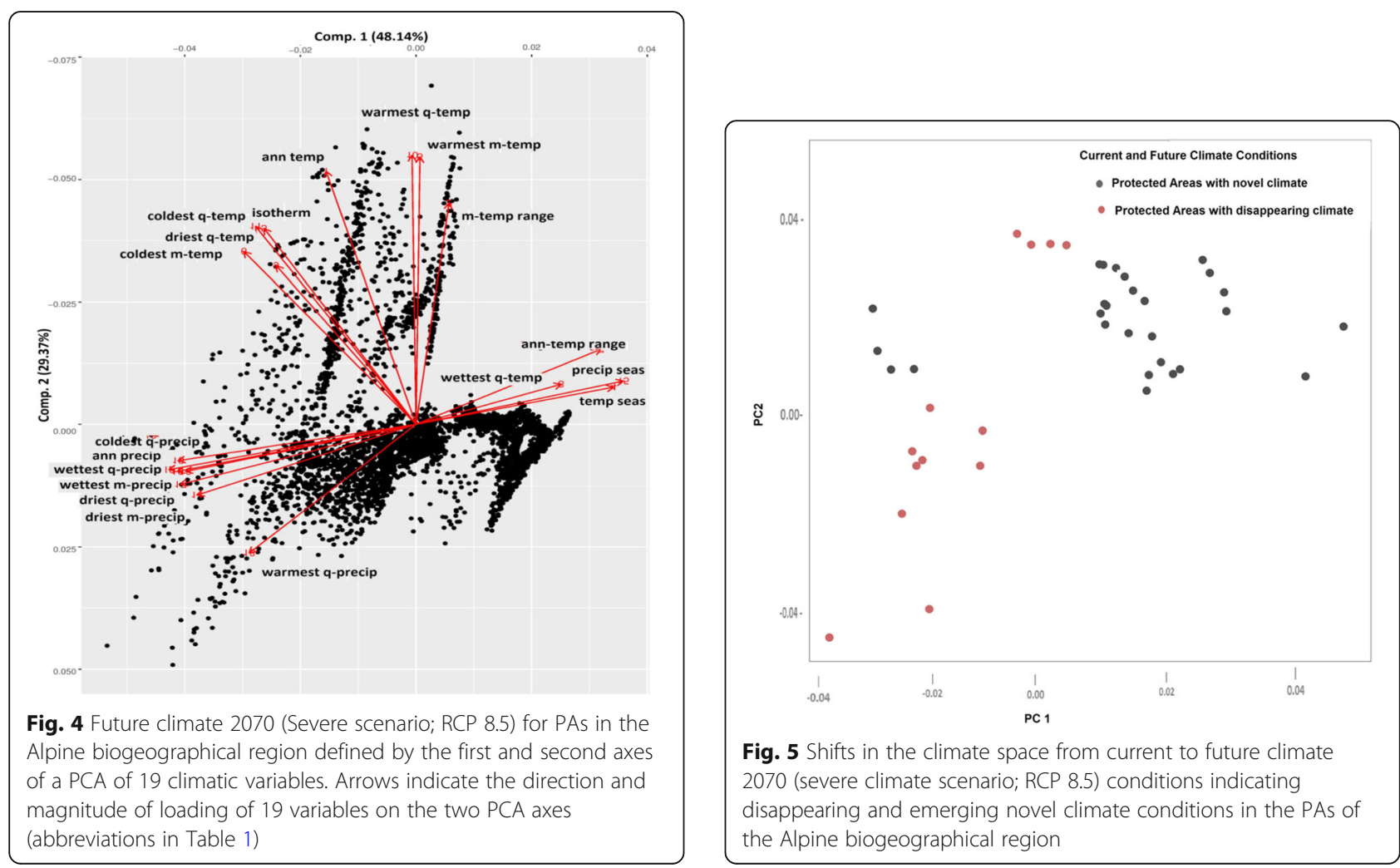


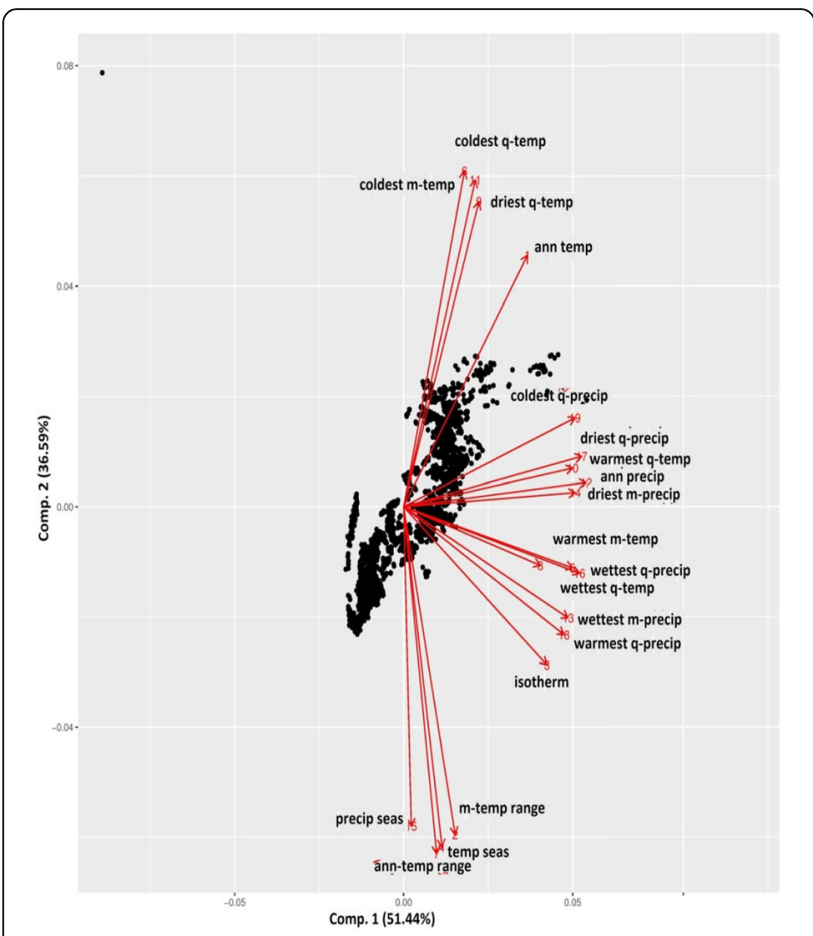

Fig. 6 Current climate for the selected 404 PAs in the Boreal biogeographical region defined by the first and second axes of a PCA of 19 climatic variables. Arrows indicate the direction and magnitude of loading of 19 variables on the two PCA axes (abbreviations in Table 1)

warmest month in 2070. PC1 suggests that annual temperature range is very strongly correlated with temperature seasonality (Fig. 7). Wettest quarter precipitation is positively associated while the warmest month temperature has negative loadings on PC2 (Table 3).

\section{Climate space shift from current to future climate (RCP 8.5) in the Boreal biogeographical region}

Figure 8 shows the novel and disappearing climates at the edges of the climate space. The results showed that 10 of selected 404 PAs of the Boreal region will experience new emerging climate conditions while 07 PAs will experience disappearing climate in 2070 (RCP 8.5). The novel climate conditions are found on the periphery of current climate space (Fig. 8).

\section{Current climate space in the PAs of the Continental biogeographical region}

The first four components showed the eigenvalues ( $\mathrm{PC} 1$ $=8.22, \mathrm{PC} 2=4.60, \mathrm{PC} 3=3.09, \mathrm{PC} 4=1.49)$ greater than 1 in the current climate space of the selected 153 PAs of the Continental biogeographical region. The results showed that PC1 and PC2 account $68 \%$ of the total variance. Temperature seasonality and annual temperature range showed large negative loadings, while annual precipitation along with the driest and the coldest quarter precipitation showed large positive loadings on PC1 (Table 4). Annual temperature and the coldest quarter temperature showed large negative loadings on PC2. The warmest period temperature and annual temperature showed strong positive covariance (Fig. 9). The results showed that temperature and precipitation seasonality are negatively correlated with driest and coldest period precipitation (Fig. 9). The driest and the wettest period precipitation showed a strong correlation in the current climate space. There was a very strong negative correlation between the temperature of the warmest quarter and the precipitation of warmest quarter. The findings showed that precipitation variables are more associated than temperature variables (Fig. 9).

\section{Future climate space in the PAs of the Continental biogeographical region in 2050 under RCP 4.5 scenario} Mean temperature of the warmest quarter in 2050 under severe scenario has larger negative loadings compared to base climate (Table 4). The results showed temperature and precipitation seasonality are very strongly correlated in future climate space in 2050 in the PAs of the Continental biogeographical region (Fig. 10).

\section{Future climate space in the PAs of the Continental} biogeographical region in 2070 under RCP 8.5 scenario Under RCP 8.5 scenario, the first three components explain $83 \%$ of the variation in the data and these three components have eigenvalues $(\mathrm{PC} 1=7.25, \mathrm{PC} 2=5.57$, PC3 $=3.04)$ that are greater than 1 . The results showed that $\mathrm{PC} 1$ has strong positive associations with driest and warmest period precipitation in 2070, while it has more positive associations with the driest and the coldest quarter precipitation in 2050 (Table 4). Annual temperature and the warmest quarter temperature along with temperature seasonality have large negative loadings on PC1 in 2070. Precipitations of the wettest month, precipitation of the coldest quarter, and the minimum temperature of the coldest month have large negative loadings on PC2 (Table 4). Annual precipitation is more strongly correlated with the precipitation of the coldest and the wettest quarter rather than the warmest quarter in 2070 (Fig. 11).

\section{Climate space shift from current to future climate (RCP 8.5) in the Continental biogeographical region}

Figure 12 shows the novel and disappearing climates at the edges of the climate space in the Continental region. The results showed that 07 of the selected 153 PAs of the Continental region will experience new emerging climate conditions, while 07 PAs will experience disappearing climate in 2070 (Fig. 12). 
Table 3 Factor loadings of climate variables (current climate and 2070) of selected 404 N2K PAs in the Boreal biogeographical region on PCA axes 1 and 2

\begin{tabular}{|c|c|c|c|c|}
\hline \multirow[t]{2}{*}{ Climate Variable } & \multicolumn{2}{|c|}{ Factor loadings Current climate } & \multicolumn{2}{|c|}{$\begin{array}{l}\text { Factor loadings } 2070 \\
\text { (RCP 8.5) }\end{array}$} \\
\hline & $\overline{P C 1}$ & PC2 & $\overline{P C 1}$ & PC2 \\
\hline Ann temp & -0.26 & -0.23 & -0.27 & -0.25 \\
\hline M-temp range & 0.21 & 0.11 & 0.16 & -0.02 \\
\hline Isotherm & -0.14 & 0.02 & -0.18 & -0.16 \\
\hline Temp seas & 0.26 & 0.07 & 0.28 & 0.11 \\
\hline Warmest m-temp & -0.15 & -0.35 & -0.17 & -0.33 \\
\hline Coldest m-temp & -0.27 & -0.18 & -0.29 & -0.21 \\
\hline Ann-temp range & 0.27 & 0.09 & 0.29 & 0.11 \\
\hline Wettest q-temp & -0.05 & -0.15 & 0.11 & -0.16 \\
\hline Driest q-temp & -0.25 & -0.16 & -0.24 & -0.04 \\
\hline Warmest q-temp & -0.21 & -0.32 & -0.22 & -0.29 \\
\hline Coldest q-temp & -0.27 & -0.18 & -0.29 & -0.22 \\
\hline Ann precip & -0.27 & 0.21 & -0.28 & 0.24 \\
\hline Wettest m-precip & -0.17 & 0.36 & -0.16 & 0.33 \\
\hline Driest m-precip & -0.22 & 0.26 & -0.21 & 0.26 \\
\hline Precip seas & 0.22 & 0.03 & 0.13 & 0.01 \\
\hline Wettest q-precip & -0.23 & 0.29 & -0.23 & 0.31 \\
\hline Driest q-precip & -0.26 & 0.22 & -0.24 & 0.28 \\
\hline Warmest q-precip & -0.14 & 0.38 & -0.09 & 0.28 \\
\hline Coldest q-precip & -0.26 & 0.17 & -0.27 & 0.21 \\
\hline
\end{tabular}

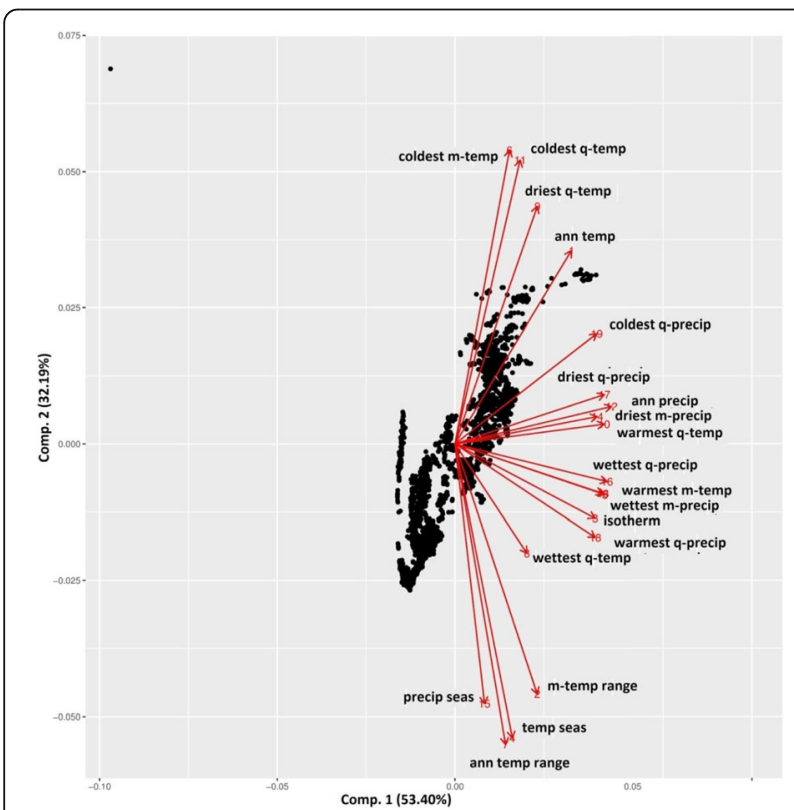

Fig. 7 Future climate of 2070 (severe scenario; RCP 8.5) for the selected 404 PAs in the Boreal biogeographical region defined by the first and second axes of a PCA of 19 climatic variables. Arrows indicate the direction and magnitude of loading of 19 variables on the two PCA axes (abbreviations in Table 1)

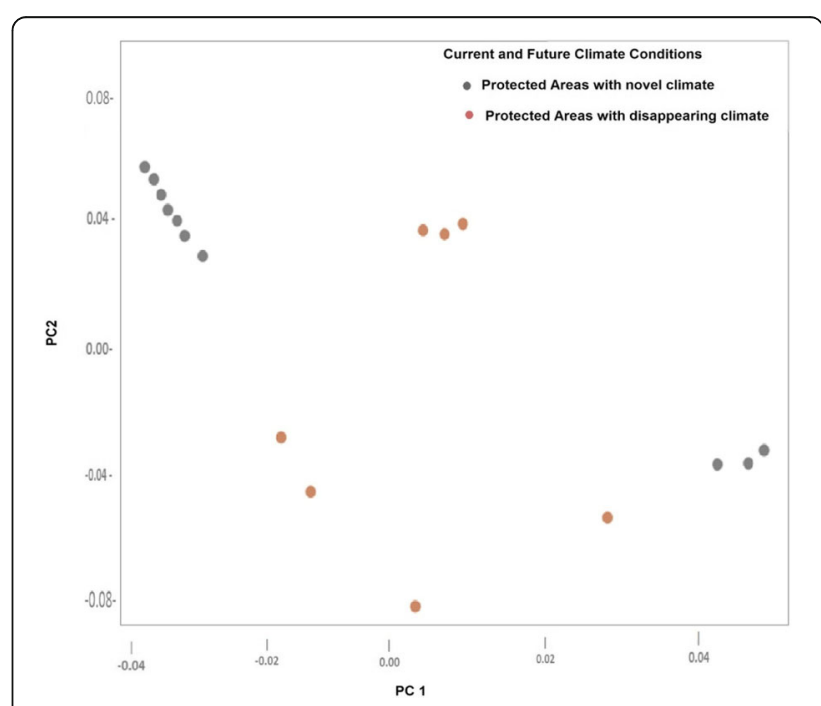

Fig. 8 Shifts in the climate space from current to future climate (2070 under severe climate scenario; RCP 8.5) conditions indicating disappearing and emerging novel climate conditions in the PAs of the Boreal biogeographical region 
Table 4 Factor loadings of climate variables (base climate, 2050 and 2070) of selected 153 N2K PAs in the Continental biogeographical region on PCA axes 1 and 2

\begin{tabular}{|c|c|c|c|c|c|c|}
\hline \multirow[t]{2}{*}{ Climate Variable } & \multicolumn{2}{|c|}{$\begin{array}{l}\text { Factor loadings } \\
\text { Base climate }\end{array}$} & \multicolumn{2}{|c|}{ Factor loadings 2050 (RCP 4.5) } & \multicolumn{2}{|c|}{ Factor loadings 2070 (RCP 4.5) } \\
\hline & $\overline{P C 1}$ & PC2 & $P C 1$ & PC2 & $\overline{P C 1}$ & PC2 \\
\hline Ann temp & -0.18 & -0.39 & -0.27 & -0.26 & -0.29 & -0.18 \\
\hline M-temp range & -0.19 & -0.05 & -0.15 & 0.05 & -0.14 & 0.11 \\
\hline Isotherm & 0.043 & 0.04 & 0.11 & 0.08 & 0.11 & 0.11 \\
\hline Temp seas & -0.29 & -0.08 & -0.29 & -0.02 & -0.29 & -0.02 \\
\hline Warmest m-temp & -0.24 & -0.31 & -0.29 & -0.18 & -0.31 & -0.11 \\
\hline Coldest m-temp & 0.018 & -0.39 & -0.11 & -0.36 & -0.17 & -0.32 \\
\hline Ann-temp range & -0.28 & -0.11 & -0.28 & -0.01 & -0.27 & 0.04 \\
\hline Wettest q-temp & -0.28 & 0.14 & -0.19 & 0.18 & -0.21 & 0.14 \\
\hline Driest q-temp & 0.06 & -0.27 & -0.13 & -0.37 & -0.18 & -0.31 \\
\hline Warmest q-temp & -0.23 & -0.34 & -0.31 & -0.21 & -0.31 & -0.14 \\
\hline Coldest q-temp & -0.05 & -0.42 & -0.18 & -0.35 & -0.22 & -0.26 \\
\hline Ann precip & 0.29 & -0.16 & 0.25 & -0.28 & 0.21 & -0.32 \\
\hline Wettest m-precip & 0.23 & -0.14 & 0.21 & -0.29 & 0.15 & -0.40 \\
\hline Driest m-precip & 0.31 & -0.14 & 0.27 & -0.07 & 0.25 & -0.09 \\
\hline Precip seas & -0.16 & 0.13 & -0.07 & -0.15 & -0.11 & -0.31 \\
\hline Wettest q-precip & 0.24 & -0.11 & 0.23 & -0.28 & 0.19 & -0.35 \\
\hline Driest q-precip & 0.31 & -0.17 & 0.27 & -0.17 & 0.26 & -0.11 \\
\hline Warmest q-precip & 0.17 & 0.15 & 0.22 & 0.08 & 0.25 & 0.08 \\
\hline Coldest q-precip & 0.32 & -0.14 & 0.24 & -0.31 & 0.21 & -0.33 \\
\hline
\end{tabular}

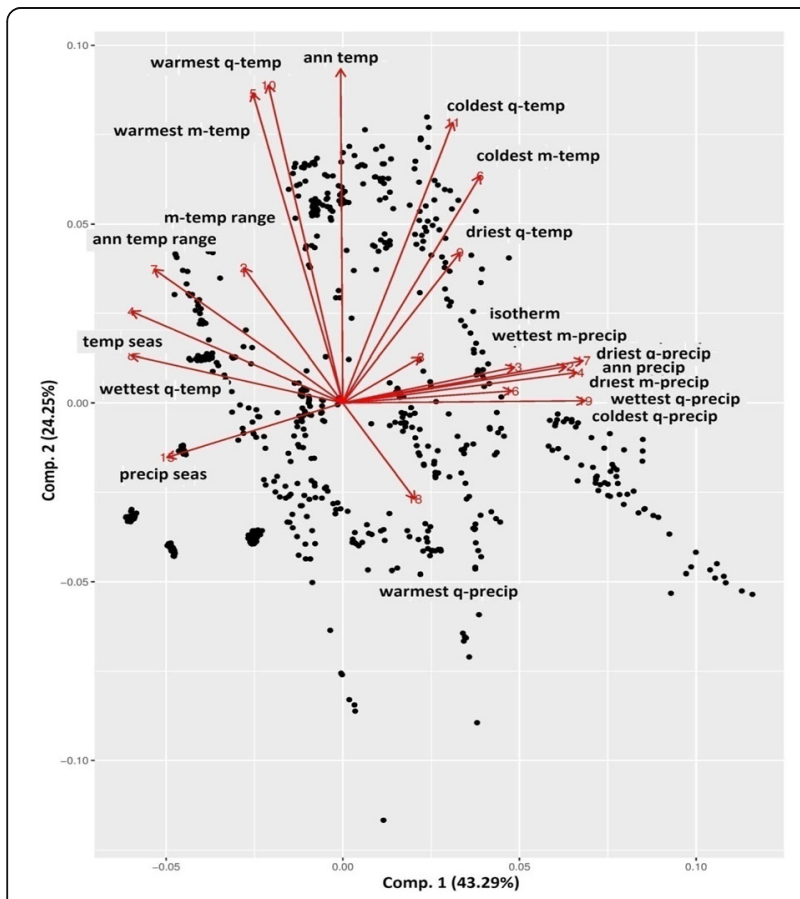

Fig. 9 Current climate for the selected 153 PAs in the Continental biogeographical region defined by the first and second axes of a PCA of 19 climatic variables. Arrows indicate the direction and magnitude of loading of 19 variables on the two PCA axes (abbreviations in Table 1)

\section{Current climate space in the PAs of the Mediterranean biogeographical region}

The first three components explained $83 \%$ of the variation in the data in base climate. The first component explained $43 \%$, and the second component explained $22 \%$. These two components have eigenvalues $(\mathrm{PC} 1=$ $8.21, \mathrm{PC} 2=4.21)$ greater than 1 . The results showed that temperature seasonality has a strong correlation with temperature range in the base climate conditions (Fig. 13). Precipitation of the driest and the warmest period has almost no correlation with the precipitation of coldest and wettest quarter (Fig. 13). Annual precipitation is more correlated with the precipitation of the wettest period than other periods. Precipitation seasonality does not vary with temperature seasonality in the Continental biogeographical region (Fig. 13). Annual mean temperature along with the temperature of the warmest and the coldest quarter has large negative loadings on component 1 (Table 5). PC1 is more positively associated with annual precipitation, precipitation of the driest quarter, and precipitation of the warmest quarter in base climate. Temperature seasonality and annual temperature range have large positive loadings and precipitation of the wettest period has large negative loadings on PC2 (Table 5). 


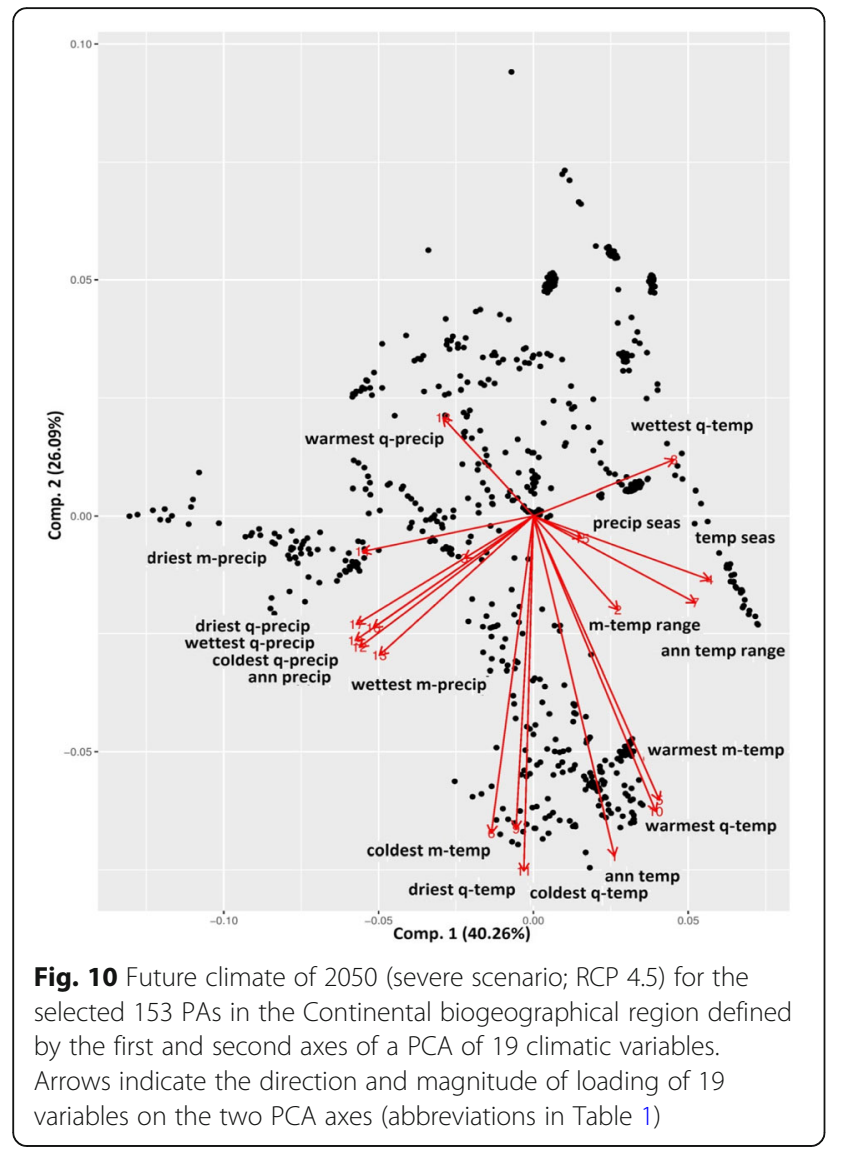

Future climate space in the PAs of the Mediterranean biogeographical region in 2050 under RCP 4.5 scenario

The results showed that precipitation seasonality is more correlated with annual mean temperature than annual precipitation in future climate conditions (RCP 4.5 scenarios). Temperature seasonality showed negative relationship with annual mean temperature in future climate under RCP 4.5. The results showed that climate conditions of the 2050s in the PAs of the Mediterranean biogeographical region are more or less similar to the base climate except seasonality. Under RCP 4.5 scenarios, PAs of the Mediterranean region will experience fewer changes (Fig. 14).

\section{Future climate space in the PAs of the Mediterranean biogeographical region in 2070 under RCP 8.5 scenario} Under RCP 8.5 scenarios, precipitation seasonality is more correlated with annual mean temperature, but not correlated with annual precipitation. There was a strong negative relationship of temperature seasonality with annual mean temperature under future climate in 2070 s. PAs of the Mediterranean region will have lower changes under RCP 8.5 scenarios (Fig. 15).

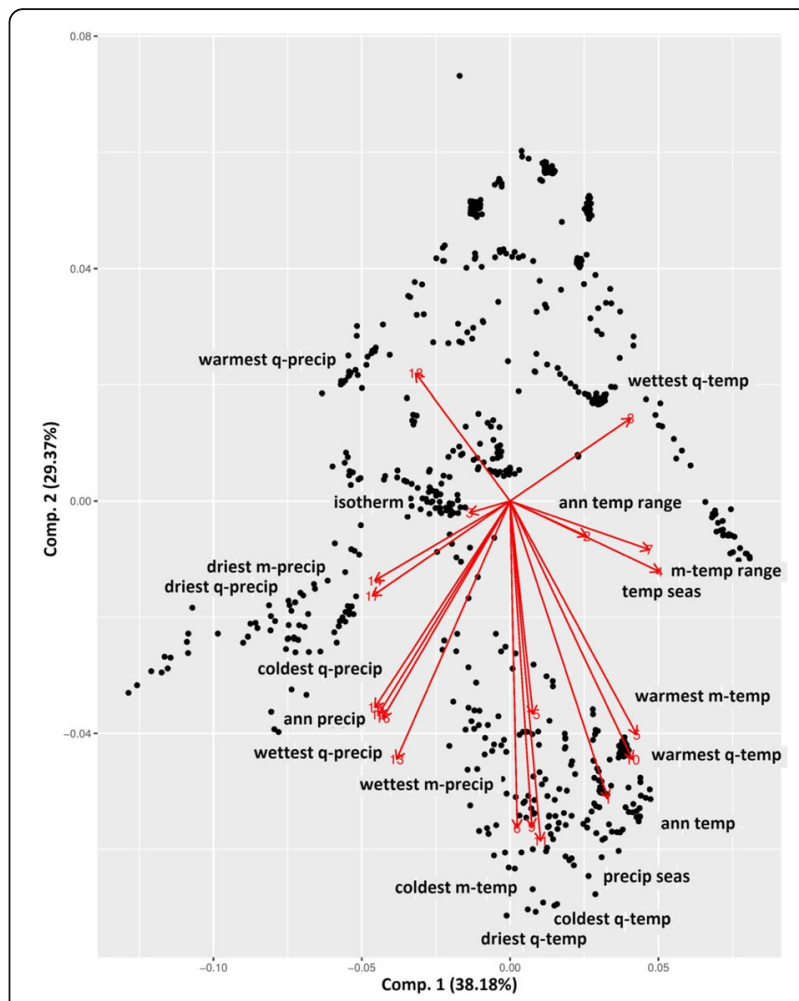

Fig. 11 Future climate of 2070 (RCP 8.5) for the selected 153 PAs in the Continental biogeographical region defined by the first and second axes of a PCA of 19 climatic variables. Arrows indicate the direction and magnitude of loading of 19 variables on the two PCA axes (abbreviations in Table 1)

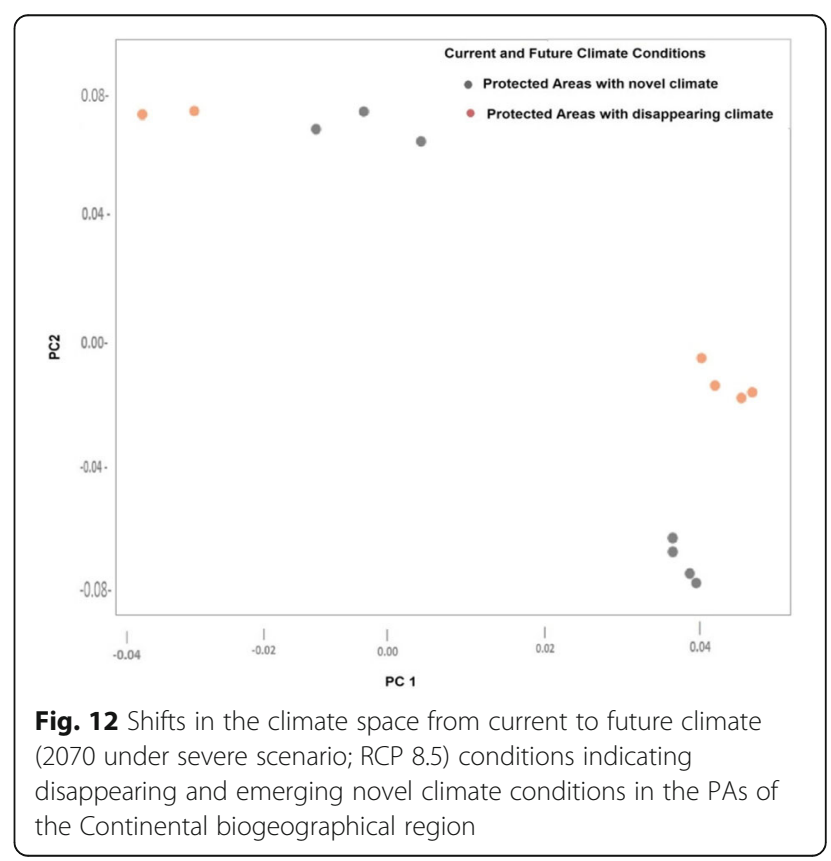




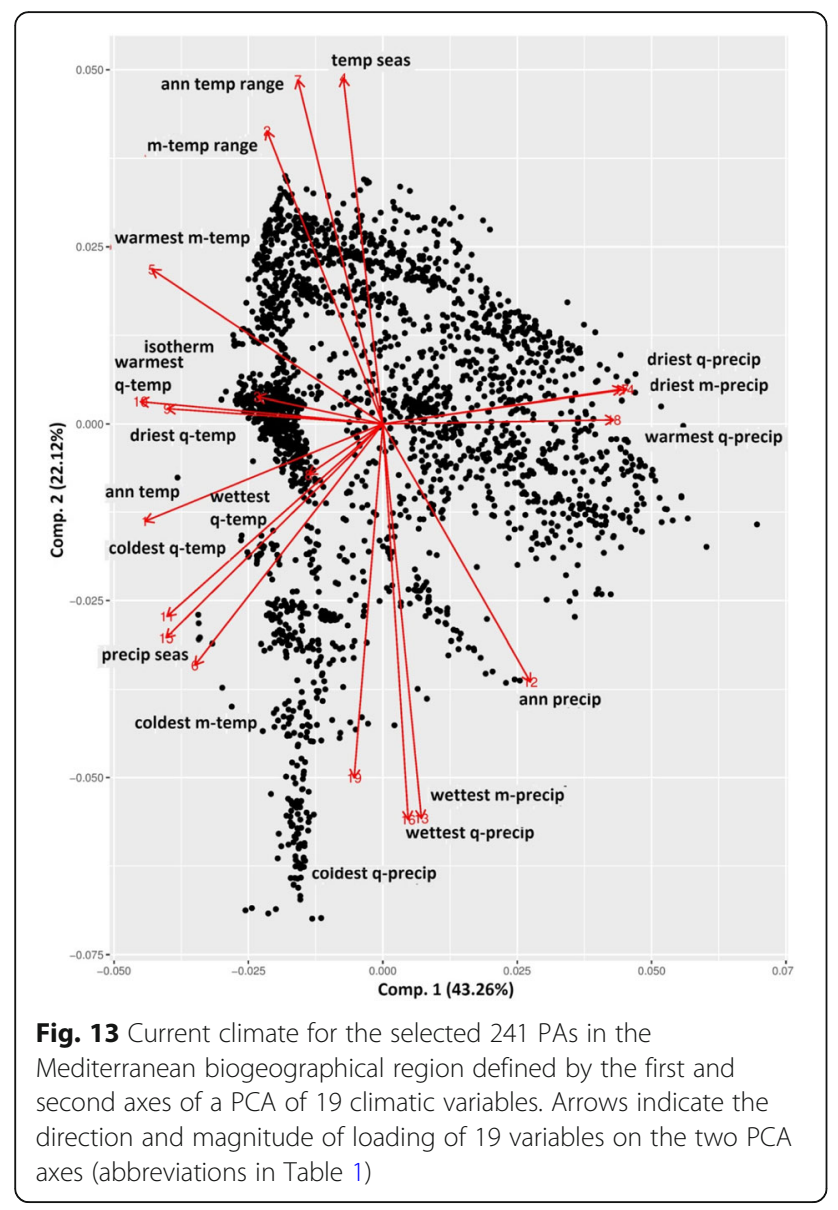

Climate space shift from current to future climate (RCP 8.5) in the Mediterranean biogeographical region

The results showed that PAs in the Mediterranean region will face more consistency of climate conditions compared to the Alpine and Boreal regions. Although PAs in this region will face emerging and disappearing climatic conditions in the future, very few numbers of PAs will experience novel and disappearing climate conditions. Only 08 PAs among the selected 241 PAs will face novel and disappearing climate conditions (Fig. 16).

\section{Discussion}

Among 19 bioclimatic variables, five variables are highly expected to experience a significant change of current conditions in 2070 of the selected 987 N2K PAs of the Alpine, Boreal, Continental, and Mediterranean biogeographical regions. These variables are annual mean temperature, temperature seasonality, annual temperature range, annual precipitation, and precipitation seasonality.

In the Alpine region, temperature rise is larger than the European average (EEA 2012). The climate of the Alps is Mediterranean in the south and temperate in the north (Condé and Richard 2005). In this study, we found that temperature rise is higher in the PAs of the Alpine
Table 5 Factor loadings of climate variables (base climate, 2050 and 2070) of selected 153 N2K PAs in the Mediterranean biogeographical region on PCA axes 1 and 2

\begin{tabular}{|c|c|c|c|c|c|c|}
\hline \multirow[t]{2}{*}{ Climate variable } & \multicolumn{2}{|c|}{$\begin{array}{l}\text { Factor loadings } \\
\text { Base climate }\end{array}$} & \multicolumn{2}{|c|}{$\begin{array}{l}\text { Factor loadings } \\
2050 \text { (RCP 4.5) }\end{array}$} & \multicolumn{2}{|c|}{$\begin{array}{l}\text { Factor loadings } \\
2070 \text { (RCP 8.5) }\end{array}$} \\
\hline & PC1 & PC2 & PC 1 & PC2 & $\mathrm{PC1}$ & PC2 \\
\hline (1) & -0.32 & 97 & 0.32 & 0.37 & -0.32 & -0.08 \\
\hline - & -0.02 & (3) & -0.05 & 0.11 & -0.06 & 0.39 \\
\hline therm & -0.06 & $x_{0}+2+2$ & 0.08 & 0.39 & -0.08 & 0.12 \\
\hline mp seas & 0.06 & 0.34 & 0.01 & 0.26 & 1 & 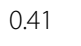 \\
\hline armest $\mathrm{m}$ & -0.26 & 0.21 & -0.24 & -0.07 & & 0.27 \\
\hline Coldest m-temp & 0.20 & 0.22 & -0.26 & -0 & 0.21 & -0.31 \\
\hline n-temp & 0.01 & 0.38 & -0.01 & 0.42 & $-c$ & 0.44 \\
\hline Wettest q-temp & 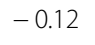 & -0.01 & B & 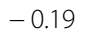 & -0.17 & -0.21 \\
\hline iest q- & -0.23 & $-c$ & -0.27 & 0.07 & $-c$ & 0.11 \\
\hline larmest q-temp & -0.32 & 0.04 & -0.31 & 0.08 & -0.30 & 0.09 \\
\hline Diaest q- & -0.31 & -0.15 & -0.29 & -0.21 & -0.28 & -0.23 \\
\hline T & 025 & -0.24 & 0.26 & -0 & 0.2 & -0 \\
\hline elciest m-precip & 0.09 & -1 & 0.07 & -0 & 0.13 & -0.21 \\
\hline jies & 0.33 & 0.01 & 0.32 & 0.04 & 0.31 & 0.08 \\
\hline sects & -0. & 9 & 6 & -0 & -5 & -0.19 \\
\hline Wettest q-precip & 0.09 & -0.36 & 0.11 & -0.27 & 0.17 & -0.19 \\
\hline iest q-precip & 0.32 & 0.01 & 0.31 & 0.02 & 01 & 0.07 \\
\hline Warmest q-precip & 0.30 & -0.02 & 0.29 & -0.04 & 0.28 & -0.01 \\
\hline oldest q-precip & 0.03 & -0.31 & 0.08 & -0.11 & 0.15 & -0.1 \\
\hline
\end{tabular}

region compared to the other biogeographical regions (Fig. 17). As a result, PAs in this area experience more new emerging and disappearing climate conditions (Fig. 5). An increase in annual mean temperature will be observed all over the region (Fig. 17). The rise in temperature causes decreases in glacier extent and volume and therewith a decline in the ski tourism (EEA 2012). Disappearing climate in the N2K PAs of the Alpine region will cause an upward shift of plant and animal species and high risk of species extinctions (EEA 2012). As a result, it could increase the risk of rock falls, landslides, and forest pests (EEA 2012) in the PAs. Alternatively, the emerging climate conditions will form the setting for the development of assemblage of species (Wiens et al. 2011) that are new to N2K PAs of the Alpine region. The decrease in temperature seasonality has been observed in the Alpine region (Fig. 18). It appears that the difference between the annual maximum and minimum temperatures will decline in the PAs of the Alpine region which could lead to more new conditions in climate (Xu et al. 2013) along with a more rising annual temperature. The change has been noticed in the maximum temperature of the warmest period and the minimum temperature of coldest month. The temperature of the coldest period will increase more 


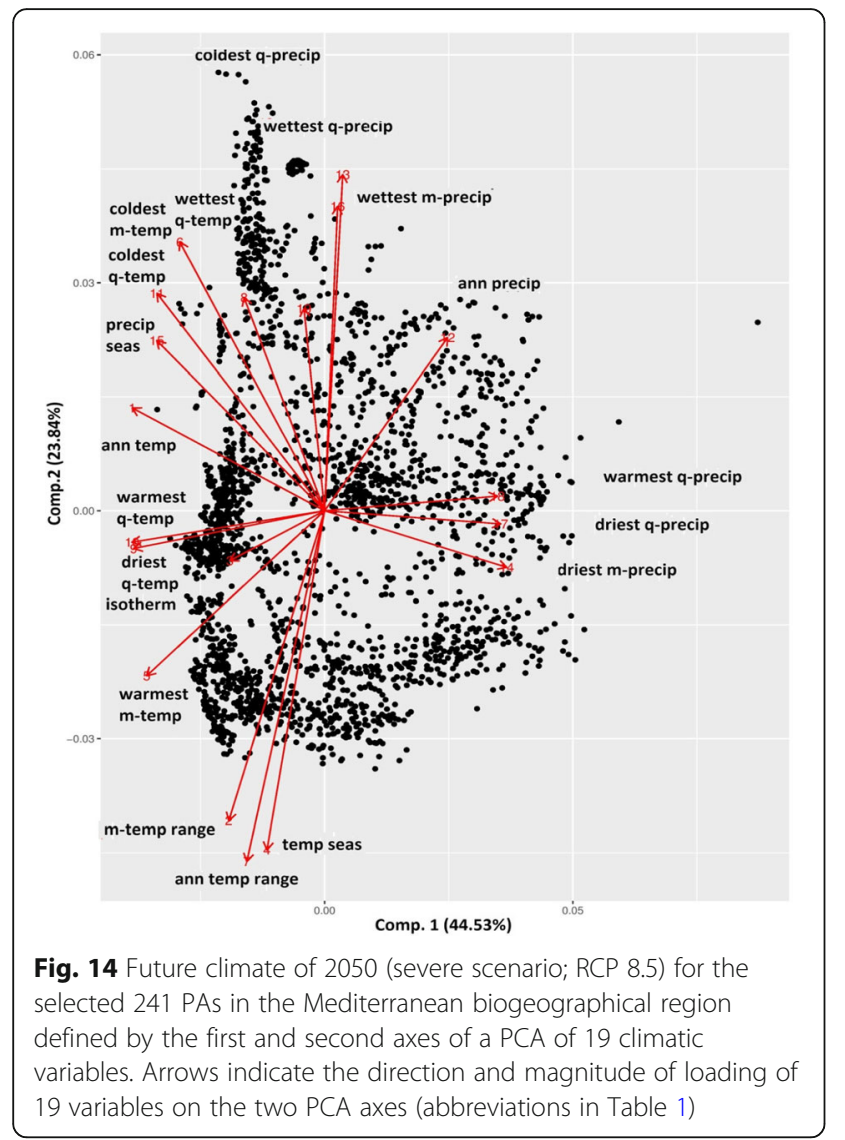

than that of the warmest period. These changes in climate may alter vegetation productivity or modify vegetation seasonality over time (Xu et al. 2013). The rise of annual mean temperate will be profound in all the PAs of the Boreal region (Fig. 17). The southern part of this region dominated by deciduous trees may slowly shift northwards with increasing temperature (Condé et al. 2003).

Precipitation seasonality will decrease in the future in the Alpine region (Fig. 19). The ecosystem of the PAs in this mountainous region is highly vulnerable to such changes (Rubin et al. 2005). This area represents an extreme fauna and flora and a high level of endemism (Rubin et al. 2005). Changes in climate conditions alter the distribution of species and the composition of species (Langdon and Lawler 2015). Therefore, species will tend to shift beyond their current range (Langdon and Lawler 2015). About $8786 \mathrm{~km}^{2}$ areas $(17.70 \%$ of the total selected PAs in the Alpine region) of the selected N2K PAs in this region will face a new emerging climate while approx. $1695 \mathrm{~km}^{2}$ of climate space will disappear in 2070 (Table 6). As a result, current boundaries of PAs in this region will not be suitable to hold present species under future climate. To sum up, the climate parameters of the PAs in the Alpine region will experience changes
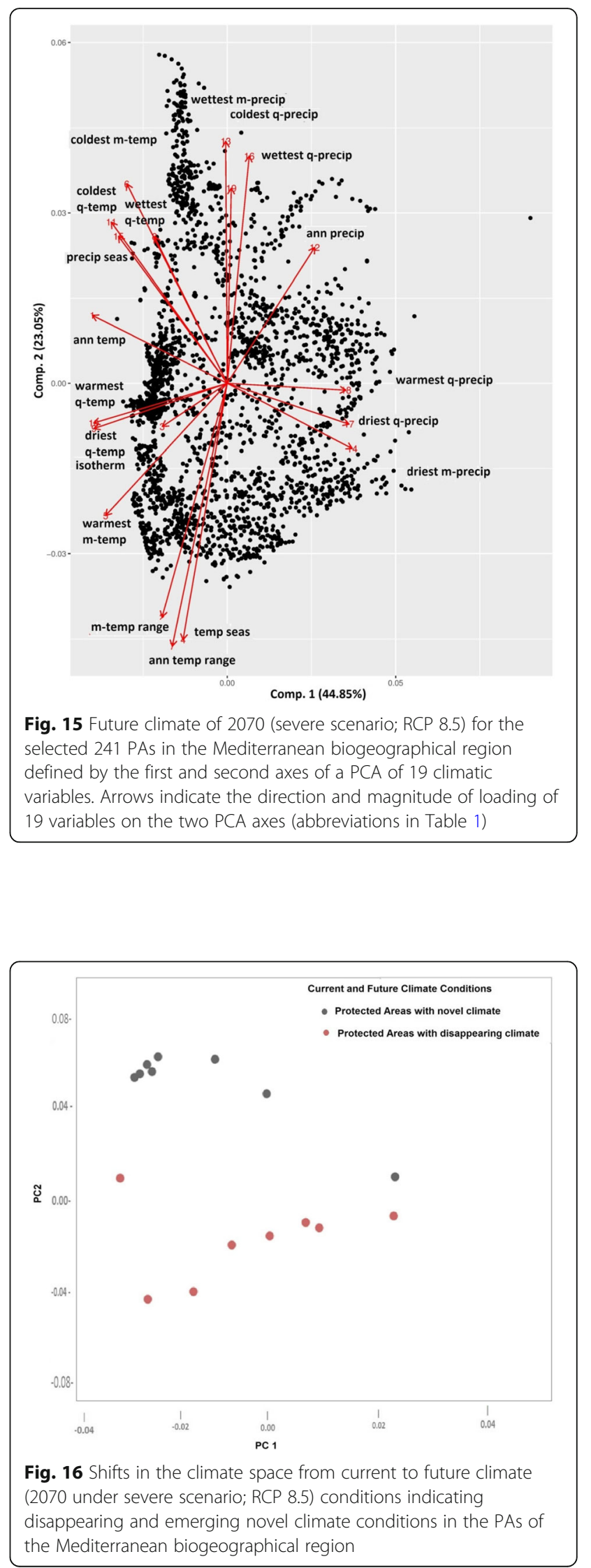

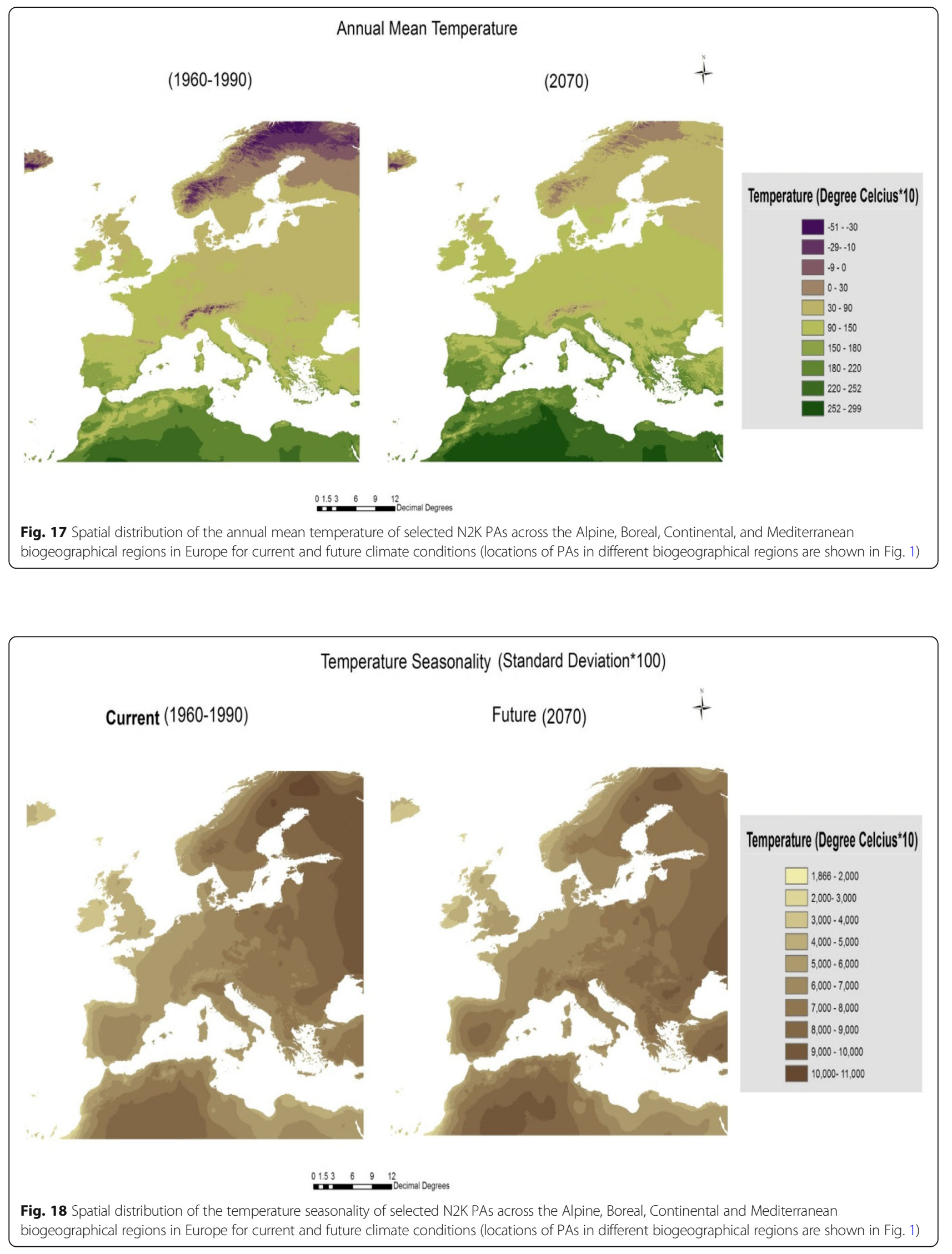


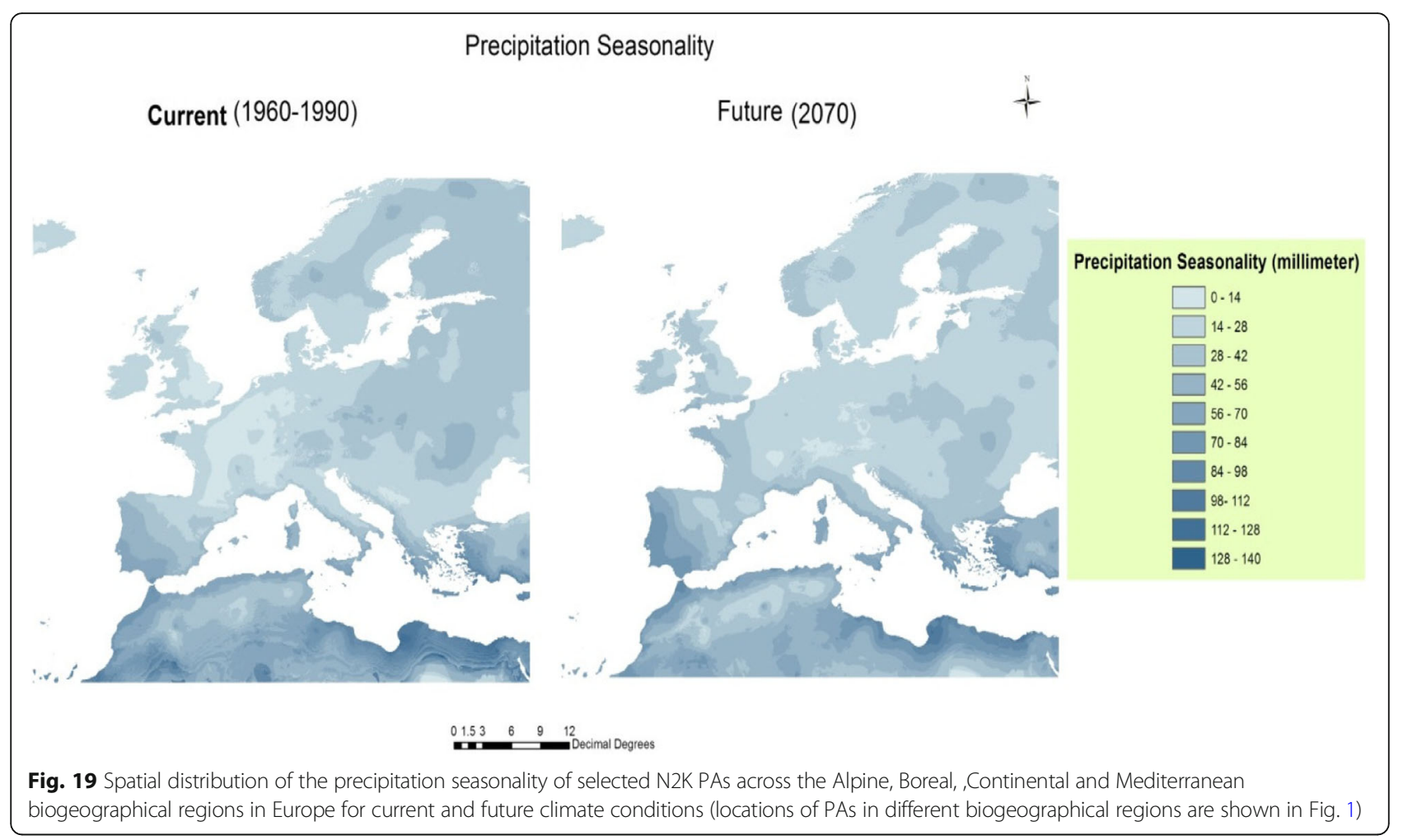

in annual trends, seasonality, and extreme factors which lead to the new emerging and the disappearing climate conditions.

The rise of annual mean temperate will be profound in all the PAs of the Boreal region (Fig. 17). The southern part of this region dominated by deciduous trees may slowly shift northwards with increasing temperature (Condé et al. 2003). The increase of the warmest period precipitation and the decrease in precipitation seasonality will be the major changing conditions from current to future climate. With these changes compared to the current climate, the Boreal region will experience fewer variations of climate conditions over geographic space in future. In 2070, the climate conditions of the PAs in the Boreal region will have fewer variations over the geographic landscape. With increasing precipitation, the forest areas are increasing (Sundseth 2005). Forests are getting more uniform with fewer tree species and less biodiversity in the region (Condé et al. 2003). Some small grassland patches that are rich in species will disappear (Condé et al. 2003) with disappearing climate in the future. The decrease in temperature seasonality and annual temperature range in 2070 will enhance the development of novel climate conditions (Fig. 20). About $1.73 \%$ of the areas of the selected N2K PAs in the Boreal region will experience new emerging novel climate conditions in 2070 while only $0.90 \%$ areas of current climate will disappear in the future (Table 6). Conservation status is comparatively poor in the Boreal region (Gauthier et al. 2015). Furthermore, under the Habitats Directive nearly one half of the habitats have an unfavorable conservation status and are declining in the Boreal region (Gauthier et al. 2015). In this situation, emerging of new climate conditions and the disappearing of the current climate in future may lead to more vulnerable ecosystems of N2K PAs in the Boreal biogeographical region.

The rise of annual mean temperature is much more asymmetrical over the geographic landscape in the PAs of the Continental region compared to other regions (Fig. 17). An increase of the warmest and the coldest quarter precipitation will be expected in 2070 in this region. The increase of the precipitation will increase the

Table 6 The land area $\left(\mathrm{km}^{2}\right)$ of selected N2K PAs that is classified as novel or disappearing climate in different biogeographical regions in 2070 under the severe scenario (RCP 8.5)

\begin{tabular}{lllll}
\hline Climate type & Alpine & Boreal & Continental & Mediterranean \\
\hline Novel & $8786(17.70 \%)$ & $860(1.73 \%)$ & $176(2.13 \%)$ & $986(2.35 \%)$ \\
Disappearing & $1695(3.41 \%)$ & $448(0.90 \%)$ & $110(1.04 \%)$ & $786(1.87 \%)$ \\
All selected PAs & $49,639(100 \%)$ & $49,569(100 \%)$ & $8803(100 \%)$ & $41,908(100 \%)$ \\
\hline
\end{tabular}




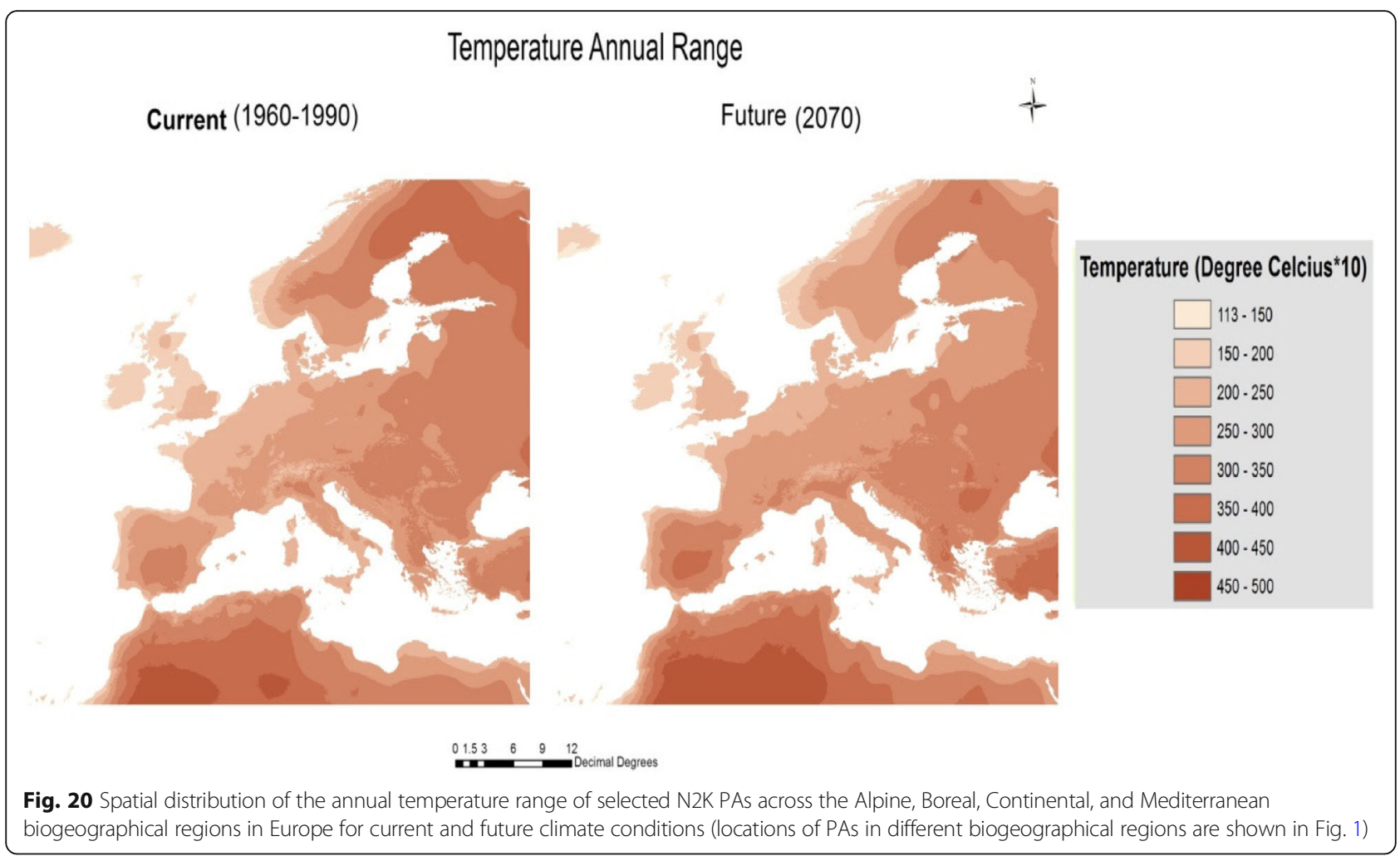

risk of river flood in this region (Condé and Richard 2004). There will be some changes in the temperature seasonality and the precipitation seasonality in the Boreal region, but the changes in climate will not be as strong in the future as in the Alpine region. As there will be some changes in climatic parameters in 2070, it will develop few novel climate conditions. The areas of about $176 \mathrm{~km}^{2}$ of the selected PAs in the Continental region will face new emerging climate while, about $110 \mathrm{~km}^{2}$ will disappear in future (Table 6). Hence, the PAs in this region will have more consistency in the climate conditions compared to other regions, though the climate will not be completely persistence of current climate in the future. The future climate of this region will be more or less the same like current climate characterized by warm summers and cold winters (Condé and Richard 2004).

PAs in the southern Mediterranean region will experience a higher rise in temperature than the northern Mediterranean region which increases the risk of biodiversity loss and shift of species (EEA 2012). A decrease in annual precipitation (Fig. 21) and an increase in the risk of drought (EEA 2012) will be observed in future. The areas of about $986 \mathrm{~km}^{2}$ and $786 \mathrm{~km}^{2}$ of the selected N2K PAs in the Mediterranean region will experience novel and disappearing climate in future (Table 6). PAs will experience more hot summers and loss of biodiversity in the future. Therefore, arid and desert conditions are increasing in this region (EEA 2012). The temperature seasonality, precipitation seasonality, and annual precipitation will decrease over this region in 2070 (Figs. 18, 19, and 20). The large increase in heat extremes, e.g., increase in the driest quarter temperature, will be found in future. These changes in climate conditions enhance the development of novel climates. The changes in climate conditions in the N2K PAs of this region may cause the loss of biodiversity (Orlikowska et al. 2016). Moreover, species which are distinctive for this region could move to other places.

According to the first hypothesis, PAs in the Alpine and the Boreal biogeographical regions will experience more newly emerging climate conditions. The results of the study support this hypothesis. About 27 PAs $\left(8786 \mathrm{~km}^{2}\right)$ of the Alpine region and 10 PAs $\left(860 \mathrm{~km}^{2}\right)$ of the Boreal region will experience novel climate conditions in the future. According to the second hypothesis, PAs in the Mediterranean and Continental biogeographical regions will face more consistency in climate conditions due to less area of disappearing and novel climate in future. The outputs of the study do partially support the second hypothesis. The climate conditions will be entirely consistent neither in the Continental region nor in the Mediterranean region in the future. PAs in the Continental region will experience very fewer changes in the future climate holding more or less the same of the current climate conditions. In the Mediterranean region, eight PAs $\left(986 \mathrm{~km}^{2}\right)$ will experience new emerging climate, and the climate conditions of eight PAs $\left(786 \mathrm{~km}^{2}\right)$ will disappear in the 


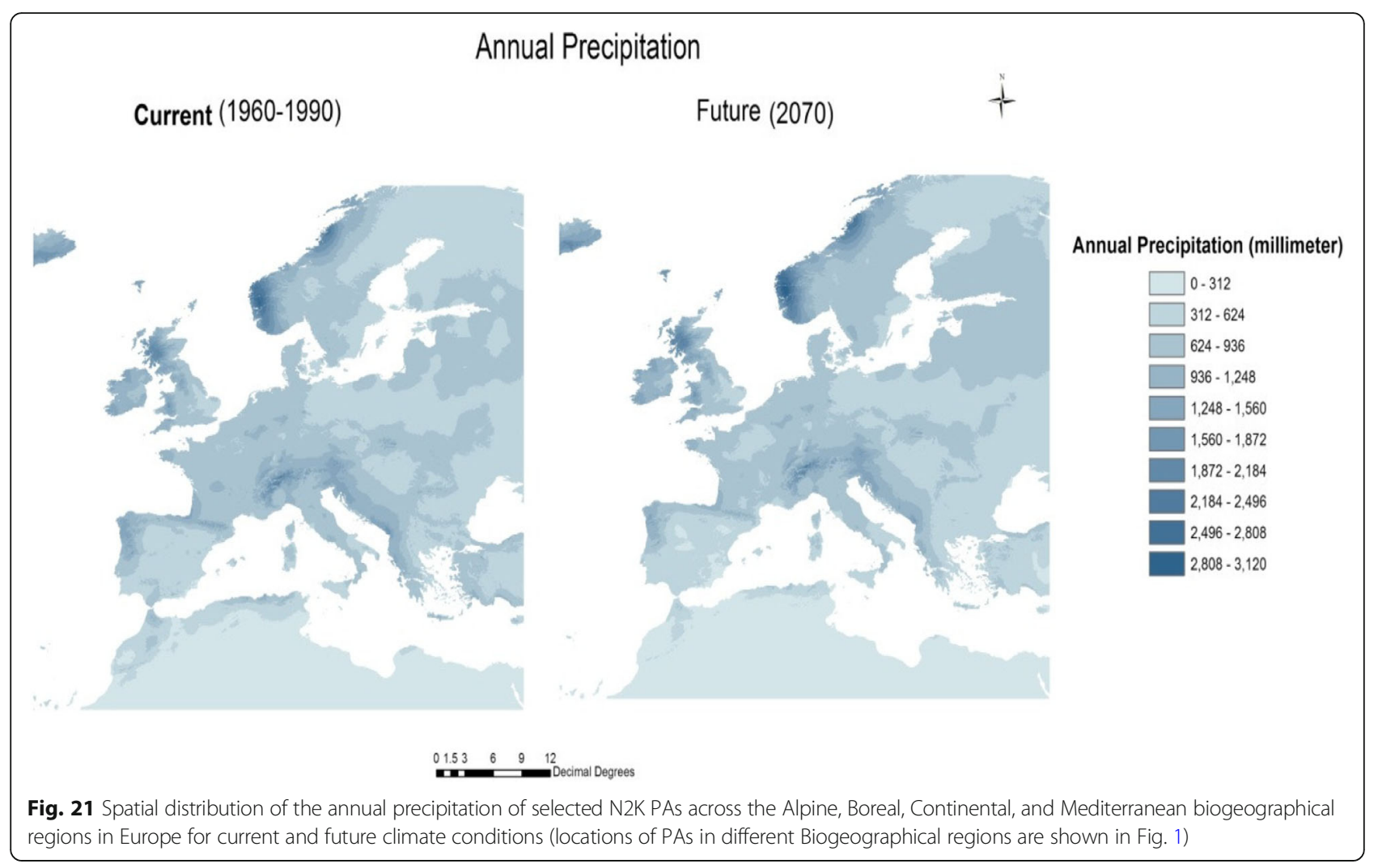

future. While comparing this with the climate conditions of the Alpine and the Boreal region, a fewer number of PAs in the Continental and the Mediterranean region will experience novel and disappearing climate conditions in the future. A large number of the N2K PAs in the Alpine region will face novel and disappearing climate conditions, and the PAs in the Continental region will have comparatively more consistency than other regions.

The N2K PAs in the biogeographical regions remain fixed in their location, but the result of this study shows climate conditions will change in the future. However, the rate of climate change is speeding up and threatens to shift ecological systems beyond the zone of current climate space (Myers et al. 2000). There will be losses and additions of species into the native communities in the PAs since climate change will cause the shift of species distribution (Wiens et al. 2011). Those species that will not move beyond the current climate space of PAs will come across novel challenges from species invading from elsewhere (Rowland et al. 2016). As a result, the interactions among species will be interrupted in the biogeographical regions (Rowland et al. 2016). All biogeographical regions experience more novel climate conditions than disappearing climates. In the PAs, a small portion of climate space is projected to disappear. Though some portion of climate space will no longer occur in the PAs of the N2K network, this does not indicate that the species that currently occupy those areas will also completely disappear. The management initiatives can hardly control the factors that decide the shift in the multivariate climate space. Hence, there are very few options to stop the disappearance of some climate conditions and the effect of those changes. The species living in disappearing climate space will need to find other places where their requirements are fulfilled. Extinction of local species is sometimes caused by disappearing climates (Myers et al. 2000). The emergence of new climate conditions forms environmental settings to welcome species being hotspots of opportunity in the future. Those portions of novel climate can be seen as a future opportunity to be a habitat for some species. Some species that are currently occupying these areas will remain in the future as well. Other species may immigrate from other PAs.

Effectiveness of PAs can not only measured by the presence of species richness, and size of the PAs, but the habitat quality, spatial configuration (Mortelliti et al. 2010), and management practices (Fahrig 2003) need to be considered. The member countries of the N2K network use a systematic monitoring program to assess the effectiveness of the studied PAs. The German National Forest Inventory addresses forest habitat types and factors to disturbance during inventory field work EC (European Commission) (2017). Each member state regularly assesses the status of all species and habitat and shares 
6-yearly progress report to the Commission as described by the Habitats Directives and the Birds Directives. In the assessment of habitat and species, member states categorize the habitat and species into four classes, e.g., favorable, unfavorable-inadequate, unfavorable-bad, and unknown. Apart from common guidelines of the N2K network, every country has its own management plan. For instance, in Wales, all PAs under N2K have a management plan which states guidelines for sites and species that need immediate action to restore or improve to favorable conservation status (EC 2014). Some member states have integrated conservation measures into their national policies and plans. For example, Belgium government incorporated the management plan of $\mathrm{N} 2 \mathrm{~K}$ network into their policies related to fishing, sand/gravel extraction, and military activities (EC 2014). In addition, the management of N2K PAs are supported by member state's other conservation programs, such as Germany contribute $€ 10$ million per year for the management of N2K PAs (EC 2014). These initiatives contribute to the effective management of the PAs of N2K.

There are some limitations in this study that need to be considered. A climate envelope model is only using information on climate variables. Climate suitability alone does not guarantee the species will be present in the PAs (Watling et al. 2013). The topography of the Alpine region is extremely complex and varied (EEA 2012). Lowland species are expected to move upwards in altitude in the face of climate change (Langdon and Lawler 2015). Highland species may experience extinction since no high grounds will be available for escape (Langdon and Lawler 2015). The mountains work as a connection, and this contributes to the climatic and biological diversity (Condé and Richard 2005). So, topography plays a significant role in the biodiversity of the Alpine region. Since the Alps originated by the collision of plates, the geological structure plays a vital role in controlling climate (EEA 2012). However, this study did not consider topography. Moreover, human activities (e.g., land-use change, atmospheric pollution, transportation, traffic-caused fragmentation) have a strong negative effect on biodiversity which could require a shift of the location of PAs (Hannah et al. 2007).

\section{Conclusion}

PAs are critical for biodiversity conservation. N2K network is designed to maintain the long-term biodiversity conservation and maintains their habitats across 07 biogeographical regions in Europe. In attempting to identify how multiple climate factors are interrelated and may change in future in the PAs, we studied all the biogeographical regions under N2K. We found that PAs in the Alpine region are under threat of novel and disappearing climate. We found five variables (annual mean temperature, temperature seasonality, annual temperature range, annual precipitation and precipitation seasonality) will have significant effects on the 987 PAs of
$\mathrm{N} 2 \mathrm{~K}$ in RCP 8.5 scenarios in four biogeographical regions. Temperature rise in the PAs of the Alpine region is higher compared to other biogeographical regions and, hence, will experience new emerging and disappearing climate conditions. Disappearing climate of the Alpine region will cause an upward shift of biodiversity and high risk of species extinction. In addition, decrease of precipitation seasonality under RCP 8.5 in the Alpine region will alter the species distribution and composition. The increase of the warmest period precipitation and the decrease in precipitation seasonality in the Boreal region will be the major changing conditions from current to future climate. PAs in the Continental region will have more consistency in the climate conditions compared to other regions, though the climate will not be completely persistence of current climate in the future. Temperature seasonality, precipitation seasonality, and annual precipitation will decrease over Mediterranean region in 2070, which will lead to arid and desert conditions. About $17.70 \%\left(8786 \mathrm{~km}^{2}\right)$ of the selected PAs in the Alpine region of N2K will face a new emerging climate and $1695 \mathrm{~km}^{2}$ of climate space will disappear in 2070. About 1.73\% of the PAs in the Boreal region will experience new emerging novel climate conditions in 2070 while only $0.90 \%$ areas of current climate will disappear. Over 2\% PAs in the Continental and Mediterranean regions will experience novel climate. Immediate actions are needed to counter the upcoming changes in the climate conditions of the N2K PAs at a local, regional, and international level to ensure the persistence of many species and related ecosystem services. Conservation practices at an individual and institutional level should be interconnected and transparent to each other. PAs that are predicted to be affected by climate change will experience a decline in conservation value in the future; those PAs may benefit from the actions of reducing human disturbance and increasing connectivity among PAs, since well-connected areas may allow species to persist for longer.

\section{Abbreviations}

N2K: Natura 2000; PA: Protected area; PCA: Principal component analysis; RCP: Representative concentration pathway

\section{Acknowledgements}

We extend our gratitude to Dr. A. Jaeschke, post-doctoral researcher, Department of Biogeography, University of Bayreuth, and Prof. Dr. C. Beierkuhnlein, Chair of Biogeography, and Head of the graduate program (M.Sc.) "Global Change Ecology" (within the Elite Network of Bavaria), University of Bayreuth, Germany, for their kind supervision and necessary guidance. We are thankful to Samuel Hoffmann for his enormous help to conduct this research. We are grateful to the two anonymous reviewers, Associate Editor, and Editor-in-

Chief for their valuable comments and assistance.

\section{Funding}

International Office of the University of Bayreuth, Germany, provided generous grant for carry out the thesis works.

\section{Availability of data and materials}

The authors declare that the data and materials presented in this manuscript can be made publicly available by Springer Open as per the editorial policy. Please contact the corresponding author for data requests. 


\section{Authors' contributions}

MUSN designed the research protocol, ran the analysis, and led the writing with contributions from MLH. MLH reviewed the manuscript and made necessary corrections. Both authors read and approved the final manuscript.

\section{Authors' information}

M.U.S. Nila completed her MSc in Global Change Ecology from the University of Bayreuth, Germany. Earlier, she obtained BSc in Geography and Environment from the University of Dhaka, Bangladesh. Her research interests include spatial distribution of biodiversity, island biogeography, and climate change. M.L. Hossain is a PhD fellow (Hong Kong PhD fellowship awardee) in the Department of Geography at Hong Kong Baptist University, and Lecturer in the Department of Environmental Protection Technology at German University Bangladesh. He obtained MSc in Global Change Ecology from the University of Bayreuth, Germany, and MSc \& BSc in Environmental Science from the University of Chittagong, Bangladesh. His research interests include grassland biodiversity, global climate change, extreme events, island biogeography, and environmental management.

\section{Ethics approval and consent to participate}

Not applicable.

\section{Competing interests}

The authors declare that they have no competing interests.

\section{Publisher's Note}

Springer Nature remains neutral with regard to jurisdictional claims in published maps and institutional affiliations.

\section{Author details}

${ }^{1}$ Global Change Ecology, International Elite Study Programme, University of Bayreuth, Universitätsstraße 30, 95447 Bayreuth, Germany. ${ }^{2}$ Department of Biogeography, University of Bayreuth, Universitätsstraße 30, 95447 Bayreuth, Germany. ${ }^{3}$ Department of Geography, Hong Kong Baptist University, 15 Baptist University Road, Kowloon Tong, Hong Kong. ${ }^{4}$ Department of Environmental Protection Technology, German University Bangladesh, 1702 Gazipur, Bangladesh.

Received: 21 February 2019 Accepted: 2 April 2019

\section{Published online: 14 May 2019}

\section{References}

Araujo MB, Alagador D, Cabeza M, Nogues-Bravo D, Thuiller W (2011) Climate change threatens European conservation areas. Ecol Lett 14:484-492

Araujo MB, Cabeza M, Thuiller W, Hannah L, Williams PH (2004) Would climate change drive species out of reserves? An assessment of existing reserveselection methods. Glob Chan Biol 10:1618-1626

Beale CM, Baker NE, Brewer MJ, Lennon JJ (2013) Protected area networks and savannah bird biodiversity in the face of climate change and land degradation. Ecol Lett 16:1061-1068

Bellard C, Bertelsmeier C, Leadley P, Thuiller W, Courchamp F (2012) Impacts of climate change on the future of biodiversity. Ecol Lett 15:365-377

Brooks TM, Mittermeier RA, Fonseca GAB, Gerlach J, Hoffmann M, Lamoreux JF, Mittermeier CG, Pilgrim JD, Rodrigues ASL (2006) Global biodiversity conservation priorities. Science 313:58-61

Condé S, Richard D (2004) Europe's biodiversity- the continental biogeographical region. European Environment Agency, pp 1-52

Condé S, Richard D (2005) Europe's biodiversity- the Alpine region. European Environment Agency, Denmark, pp 1-52

Condé S, Richard D, Liamine N (2003) Europe's biodiversity-biogeographical regions and seas-the Boreal biogeographical region. European Environment Agency, Poland

Condé S, Richard D, Liamine N (2003a) Europe's biodiversity- the Mediterranean biogeographical region. European Environment Agency, pp 1-54

Condé S, Richard D, Liamine N, Leclère A (2002) Europe's biodiversitybiogeographical regions and seas- the Atlantic region, pp 1-60

Dawson TP, Jackson ST, House II, Prentice IC, Mace GM (2011) Beyond predictions: biodiversity conservation in a changing climate. Science 332:53-58

Deguignet M, Juffe-Bignoli D, Harrison J, MacSharry B, Burgess N, Kingston N (2014) United Nations list of protected areas. UNEP-WCMC, Cambridge, p 44
Development Core Team R (2013) R: a language and environment for statistical computing. R Foundation for Statistical Computing, Vienna

EC (2014) Establishing conservation measures for Natura 2000 Sites. A review of the provisions of article 6.1 and their practical implementation in different member states, $\mathrm{p} 43$

EC (European Commission), 2016. Natura 2000 sites designation. Available at: http://ec.europa.eu/environment/nature/natura2000/sites/index_en.htm

EC (European Commission), 2016a. The habitat directive. Available at: http://ec. europa.eu/environment/nature/legislation/habitatsdirective/index_en.htm

EC (European Commission) (2017) Natura 2000. Available online at: http:/ec. europa.eu/environment/nature/natura2000/index_en.htm

EEA (European Environmental Agency) (2009) Natura 2000 in the Pannonian region, $\mathrm{p} 12$

EEA (European Environmental Agency) (2012) Climate change, impacts and vulnerability in Europe: an indicator-based report. EEA Report (12)304

EEA (European Environmental Agency) (2015a) Nationally designated protected areas. Available at: https://www.eea.europa.eu/data-and-maps/indicators/ nationally-designated-protected-areas/nationally-designated-protected-areasassessment-3

EEA (European Environmental Agency) (2015b) Natura 2000 data- the European network of protected sites. Available at: https://www.eea.europa.eu/data-andmaps/data/natura-2

EEA (European Environmental Agency) (2017) Climate change, impacts and vulnerability in Europe, vol 12. EEA Report, p 2012

EEA (European Environmental Agency) (2019) An introduction to Europe's protected areas. Available at: https://www.eea.europa.eu/themes/biodiversity/ europe-protected-areas

Fahrig L (2003) Effects of habitat fragmentation on biodiversity. Annu Rev Ecol Evol Syst 34:487-515

Gauthier S, Bernier P, Kuuluvainen T, Shvidenko AZ, Schepaschenko DG (2015) Boreal forest health and global change. Science 349:819-822

Hannah L, Midgley G, Andelman S (2007) Protected area needs in a changing climate. Front Ecol Environ 5:131-138

Hansen J, Sato M, Ruedy R, Lo K, Lea DW, Medina-Elizade M (2006) Global temperature change. Proc Natl Acad Sci USA 103:14288-14293

Hartmann DJ, Klein Tank AMG, Rusticucci M, Alexander LV, Brönnimann S, Charabi Y, Zhai P (2013) Observations: atmosphere and surface. Climate change 2013: the physical science basis, Contribution of working group I to the fifth assessment report of the intergovernmental panel on climate change, pp 159-254

Hijmans RJ, Cameron SE, Parra JL, Jones PG, Jarvis A (2005) Very high resolution interpolated climate surfaces for global land areas. Int I Clim 25:1965-1978

Hole DG, Willis SG, Pain DJ, Fishpool LD, Butchart SHM, Collingham YC, Rahbek C, Huntley B (2009) Projected impacts of climate change on a continent-wide protected area network. Ecol Lett 12:420-431

Hossain ML, Beierkuhnlein C (2018) Enhanced aboveground biomass by increased precipitation in a central European grassland. Ecol Process 7:37

IPCC (2013) Climate change: impacts adaptation and vulnerability. Summary for policymakers. Intergovernmental panel on climate change. Cambridge University Press, Cambridge

Jacob D, Vautard R, Gobiet A, Sobolowski S, Kjellström E, Stegehuis A, Watkiss P, Mendlik T, Landgren O, Nikulin G, Teichmann C (2014) The European climate under a $2{ }^{\circ} \mathrm{C}$ global warming. Environ Res Lett 9(3):34006

Jenkins CN, Joppa L (2009) Expansion of the global terrestrial protected area system. Biol Conserv 142:2166-2174

Johnston A, Ausden M, Dodd AM, Bradbury RB, Chamberlain DE, Jiquet F, PearceHiggins JW (2013) Observed and predicted effects of climate change on species abundance in protected areas. Natur Clim Chan 3:1055-1061

Langdon JGR, Lawler JJ (2015) Assessing the impacts of projected climate change on biodiversity in the protected areas of western North America. Ecosphere 6:87

Leach K, Zalat S, Gilbert F (2013) Egypt's protected area network under future climate change. Biol Conserv 159:490-500

Lovejoy TE (2006) Protected areas: a prism for a changing world. Trends Ecol Evol 21:329-333

McGarigal K, Cushman S, Stafford S (2000) Multivariate statistics for wildlife and ecology research. Springer, New York

Menendez R, Gonzalez-Megias A, Collingham Y, Fox R, Roy DB, Ohlemuller R, Thomas CD (2007) Direct and indirect effects of climate and habitat factors on butterfly diversity. Ecology 88:605-611 
Mortelliti A, Amori G, Boitani L (2010) The role of habitat quality in fragmented landscapes: a conceptual overview and prospectus for future research. Oecologia 163:535-547

Myers N, Mittermeier RA, Mittermeier CG, Fonseca GAB, Kent J (2000) Biodiversity hotspots for conservation priorities. Nature 403:853-858

Orlikowska EH, Roberge JM, Blicharska M, Mikusiski G (2016) Gaps in ecological research on the world's largest internationally coordinated network of protected areas: a review of Natura 2000. Biol Conserv 200:216-227

Parmesan C (2006) Ecological and evolutionary responses to recent climate change. Ann Rev Ecol Evol Sys 37:637-669

Parmesan C, Yohe G (2003) A globally coherent fingerprint of climate change impacts across natural systems. Nature 421:37-42

Pereira HM, Leadley PW, Proenca V (2010) Scenarios for global biodiversity in the 21st century. Science 330:1496-1501

Root BA, Price JT, Hall K (2003) Fingerprints of global warming on wild animals and plants. Nature 421:47-60.

Rowland EL, Fresco N, Reid D, Cooke HA (2016) Examining climate-biome shifts for Yukon and its protected areas. Glob Ecol Conserv 8:1-17

Rubin CA, Eriksson M, Fritz M (2005) Natura 2000 in the Alpine region. European Commission Environment Directorate-General, Luxembourg

Stocker TF, Qin D, Plattner GK, Tignor M, Allen SK, Boschung J, Nauels A, Xia Y, Bex V, Midgley PM (eds.) (2015) Summary for Policymakers. In: Climate Change 2013: The Physical Science Basis. Contribution of Working Group I to the Fifth Assessment Report of the Intergovernmental Panel on Climate Change, CEUR Workshop Proceedings 1542:33-36. arXiv:arXiv:1011.1669v3, https://doi.org/10.1017/CBO9781107415324.004

Stolton S, Dudley N, Avcıoğlu Çokçalışkan B, Hunter D, Ivanić KZ, Kanga E, Kettunen et al (2015) Values and benefits of protected areas. In: Worboys GL, Lockwood M, Kothari A, Feary S, Pulsford I (eds) Protected area governance and management. ANU Press, Canberra, pp 145-168

Sundseth K (2005) Natura 2000 in the Atlantic region. European Commission Environment Directorate-General, Luxembourg

Sundseth K (2005a) Natura 2000 in the Boreal region. European Commission Environment Directorate-General, Luxembourg

Sundseth K (2005b) Natura 2000 in the Continental region. European Commission Environment Directorate-General, Luxembourg

Sundseth K (2005c) Natura 2000 in the Macaronesian region. European Commission Environment Directorate-General, Luxembourg

Sundseth K (2009) Natura 2000 in the Mediterranean region. European Commission Environment Directorate-General, Luxembourg

Thomas CD, Gillngham PK (2015) The performance of protected areas for biodiversity under climate change. Biol J Linn Soc 115:718-730

Thompson J, Peepre J (2014) Economic benefits of protected areas to community and tourism, pp 1-39

Watling JI, Brandt LA, Mazzotti FJ, Romanach SS (2013) Use and Interpretation of Climate Envelope Models: A Practical Guide. University of Florida, Gainesville, FL, pp 43. http://crocdoc.ifas.ufl.edu/projects/climateenvelopemodeling/ publications/Use\%20and\%20Interpretation\%20of\%20Climate\%20Envelope \%20Models\%20-\%20A\%20Practical\%20Guide.pdf

Wiens JA, Seavy NE, Jongsomij D (2011) Protected areas in climate space: what will the future bring? Biol Conserv 144:2119-2125

Wiens JJ, Ackerly DD, Allen AP, Anacker BL, Buckley LB, Cornell HV, Damaschen El et al (2010) Niche conservatism as an emerging principle in ecology and conservation biology. Ecol Lett 13:1310-1324

Willis SG, Hole DG, Collingham YC, Hilton G, Rahbek C, Huntley B (2009) Assessing the impacts of future climate change on protected area networks: a method to simulate individual species' responses. Environ Manag 43:836-845

Xu L, Myneni RB, Chapin FS III, Callaghan TV, Pinzon JE, Tucker CJ et al (2013) Temperature and vegetation seasonality diminishment over northern lands. Natur Clim Chang 3:581-586

Zomer RJ, Xu J, Wang M, Trabucco A, Li Z (2015) Projected impact of climate change on the effectiveness of the existing protected area network for biodiversity conservation within Yunnan Province, China. Biol Conserv 184:335-345

\section{Submit your manuscript to a SpringerOpen ${ }^{\circ}$ journal and benefit from:}

- Convenient online submission

- Rigorous peer review

- Open access: articles freely available online

- High visibility within the field

- Retaining the copyright to your article

Submit your next manuscript at $\boldsymbol{\nabla}$ springeropen.com 